Ife Journal of Science vol. 20, no. 3 (2018)

\title{
SYNTHESES, CHARACTERIZATION AND CHELATING PROPERTIES OF GUANIDOBENZIMIDAZOLE AND GUANIDOPHOSPHONATEBENZIMIDAZOLE
}

\author{
Aremu, J. A, *Durosinmi, L. M., Oluyemi, E.A. and Ojo, I.A.O. \\ Department of Chemistry, Obafemi Awolowo University, Ile-Ife, Nigeria. \\ *Corresponding Author: lateefahdurosinmi@yahoo.com; ldurosinmi@oauife.edu.ng. \\ (Received: $13^{\text {th }}$ February, 2018; Accepted: $10^{\text {th }}$ October, 2018)
}

\section{ABSTRACT}

\begin{abstract}
The synthesis of guanidine derivatives of benzimidazole namely, guanidinobenzimidazole, (GBM), guanidinophosphonatebenzimidazole, (GPBM), and their chelating properties are reported in this work. The guanidine and phosphonate derivatives were synthesized along with their metal complexes, Fe(II), $\mathrm{Co}$ (II), Ni(II) $\mathrm{Cu}(\mathrm{II})$ and $\mathrm{Zn}(\mathrm{II})$. The ligands were characterized by ${ }^{1} \mathrm{H} \mathrm{NMR},{ }^{13} \mathrm{C}$ NMR spectroscopy while both the ligands and the metal complexes were characterized by C.H.N analysis, Percentage Metal Composition, FT-Infrared spectra Analysis , UV-Visible Electronic Spectroscopy and Magnetic susceptibility measurements. The results from the percentage composition of the metals in the complexes suggest that ratio of the metal to ligand is 1:2 (M: L) where $\mathrm{M}=\mathrm{Co}(\mathrm{II}), \mathrm{Ni}(\mathrm{II}), \mathrm{Cu}(\mathrm{II}), \mathrm{Fe}(\mathrm{II}), \mathrm{Zn}(\mathrm{II})$. Thus, the prepared complexes have the general formulae $\left[\mathrm{ML}_{2}\right]$. Electronic Spectral analyses indicated the participation of the imidazolic nitrogen atom and the nitrogen in position 12 of the guanidinobenzimidazole ligand in the coordination of the ligand to the metal ions while, the shifts in the position of ther $(\mathrm{P}=\mathrm{O})$ absorption band of the phosphonate moiety in the guanidinophosphonatebenzimidazole, (GPBM) ligand from $1265 \mathrm{~cm}^{-1}$ in the free ligand to $1141-1200 \mathrm{~cm}^{-1}$ in the metal complexes suggested that the $\mathrm{P}=\mathrm{O}$ is most likely involved together with the nitrogen atom in position 12 in the coordination of the metal ions to the guanidinophosphonatebenzimidazole, (GPBM) ligand. The electronic spectral data and the values of the magnetic susceptibility values suggest six coordinate octahedral/ distorted octahedral geometry for all the complexes.
\end{abstract}

Keywords: Characterization, Chelating properties, Guanidine derivatives, Metal Complexes, Synthesis.

\section{INTRODUCTION}

Coordination compounds containing benzimidazole derivatives and transition metal ions continue to attract the interest of research groups, partly due to their very interesting chemistry as well as their possible applications including biological properties, (Malek et al., 2006).

Similarly, transition metal complexes of guanidine and phosphonates have been found to have good chelating capability, structural flexibility, interesting electrical as well as magnetic properties (Anitha, 2011). They are also known to possess antimicrobial potentials (Gupta et al., 2009; Rajeeva et al., 2009). Thus, guanidines, phosphonates and their complexes continue to receive attention both in academic research and industrial development as compounds with unique properties. Phosphonates are increasingly used in medicine to treat disorders associated with bone formation and calcium metabolism. They also serve as carriers for radionuclides in bone cancer treatments (Malek et al., 2006).
The coordination of 2-benzimidazole derivatives to metal ions has been shown to occur through a variety of sites, with groups bearing nitrogen, oxygen, sulphur and other donor atoms. The coordination occurs through the imidazolic nitrogen atom and also through $\mathrm{N}, \mathrm{S}$ or $\mathrm{O}$ atoms present in the molecule, giving place to a variety of metal-ligand coordination modes, (Fabiola T, et al, 2008).

In spite of this great chelating properties, biochemical and pharmaceutical importance of benzimidazoles and guanidines, phosphorylation of guanidinobenzimidazole, its structural activities as well as the chelating properties of Guanidinophosphonatebenzimidazole, (GPBM) have not been reported. Thus, this work focused on the synthesis of Guanidinobenzimidazole, (GBM) and Guanidinophosphonate benzimidazole, (GPBM) ligands; investigated their chelating properties/differences and characterized these ligands as well as their metal complexes. 


\section{MATERIALS AND METHODS \\ Materials}

High grade analytical chemicals and reagents were used and these included: 2-amino benzimidazole, silica gel, copper(II) sulphate, tetrahydrofuran, triethylamine, dimethylphosphite, perchloric acid, disodium ethylene diamine tetra acetic acid ( EDTA ), zinc(II) sulphate, ammonia solution, ammonium chloride, erichrome black $\mathrm{T}$ indicator, sodium hydroxide, methyl thymol blue indicator, Iron(II ) chloride, cobalt(II) nitrate, nickel (II) nitrate, copper (II) nitrate, zinc(II) nitrate. These were all purchased from Sigma Aldrich.

\section{Instrumentation}

The NMR spectra were recorded on AgilentNMR-400 MHz Spectrometer; TMS was used as the internal standard. IR spectra $\left(4000-400 \mathrm{~cm}^{-1}\right)$ were recorded on Shimadzu FTIR- 8700 Spectrophotometer. The C.H.N elemental analyses were carried out on Perkin Elmer 240 C elemental analyzer and the electronic transitions using the T92-UVWin UV Visible Spectrophotometer.

Melting points of the samples were determined by using the Electro thermal Digital Melting Point Apparatus. The magnetic susceptibility measurements of the metal complexes were made at room temperature using MSB-MK1 Sherwood Susceptibility Balance.

\section{Synthetic Methods}

\section{Guanidination and Phosphorylation of} Benzimidazole.

Thiourea is converted into guanidinesin a suitable solvent such as tetrahydrofuran and chloroform containing copper sulphate - silica gel in presence of tertiary amines, (Alan and Boris, 2005).

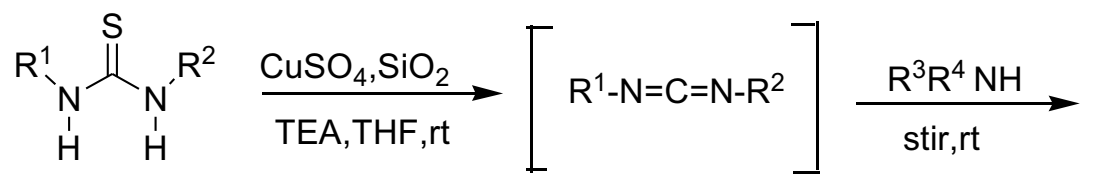

$\mathrm{R}^{1}, \mathrm{R}^{2}, \mathrm{R}^{3}, \mathrm{R}^{4}=\mathrm{H}$.

The synthesis of guanidinobenzimidazole and guanidinophosphonatebenzimidazole were carried out according to the methods of Alan, 2005 and Krishnamurthy, 1995.

\section{Synthesis of Guanidinobenzimidazole, (GBM).}

Copper(II) sulphate and silica gel (1 g each) were added to $25 \mathrm{ml}$ of tetrahydrofuran in a $250 \mathrm{ml}$ round bottomed flask in the presence of $2 \mathrm{ml}$ triethylamine in a $250 \mathrm{ml}$ round bottom flask.
Thiourea (1), $3.81 \mathrm{~g}(50 \mathrm{mM})$ was added and the solution was stirred at room temperature for $6 \mathrm{hr}$. to produce carbondiamide (2) intermediate. The intermediate was reacted with $50 \mathrm{mM}$ of 2 aminobenzimidazole (3) by stirring again for $6 \mathrm{hr}$ at room temperature. Crystals of guanidinobenzimidazole (4) produced were filtered and the filtrate was concentrated by using rotary evaporator. The crystals were washed with few $\mathrm{mls}$ of tetrahydrofuran and dried over activated silica gel in a desiccator, (Alan and Boris, 2005).

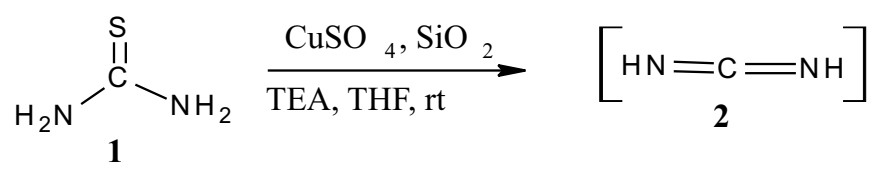

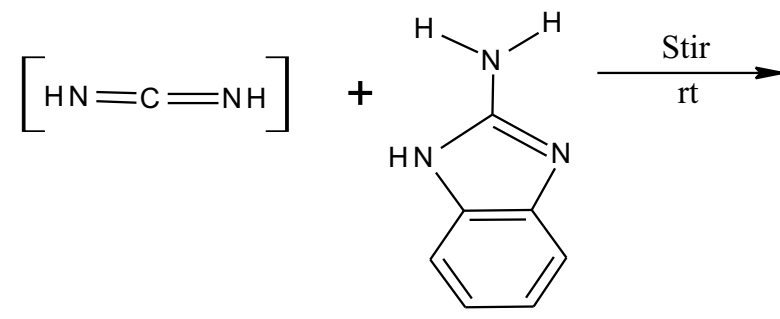

3<smiles>N=C(N)Nc1nc2ccccc2[nH]1</smiles> 
Synthesis of Guanidinophosponate for another $8 \mathrm{hr}$.

\section{benzimidazole, (GPBM)}

Excess paraformaldehyde (6) was reacted with guanidinobenzimidazole (5) $(5 \mathrm{mM}, 0.96 \mathrm{~g})$ and 60 mg of silica-supported perchloric acid was stirred for $8 \mathrm{hr}$ in $25 \mathrm{ml}$ of ethanol. Dimethylphosphite (7) $(50 \mathrm{mM}, 4.50 \mathrm{ml})$ was then added and the stirring continued for $1 \mathrm{hr}$ at room temperature in an oil bath and then refluxed at $80^{\circ} \mathrm{C}$ with stirring

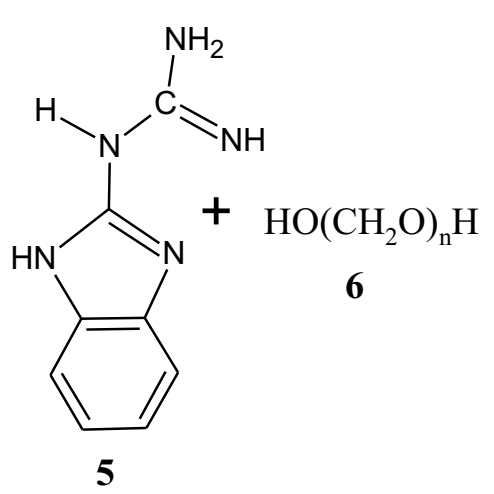

Synthesis of Metal Complexes of Guanidinobenzimidazole and Guanidinophosponatebenzimidazole.

The syntheses were carried out according to the method of Anitha et al., (2011) and Bakir et al., (2013).

Equimolar quantities, $(0.5 \mathrm{mM})$ of the ligand and metalsalt, $\left(\mathrm{Co}\left(\mathrm{NO}_{3}\right)_{2}, \quad \mathrm{Ni}\left(\mathrm{NO}_{3}\right)_{2}, \mathrm{Cu}\left(\mathrm{NO}_{3}\right)_{2}\right.$, $\mathrm{Zn}\left(\mathrm{NO}_{3}\right)_{2}$, and $\left.\mathrm{FeCl}_{2}\right)$ were reacted in $25 \mathrm{ml}$ of ethanol in a $250 \mathrm{ml}$ round bottom flask. The solution was stirred at room temperature for $18 \mathrm{hr}$. It was immediately followed by $4 \mathrm{hr}$ reflux at $80^{\circ} \mathrm{C}$ in an oil bath. The solution was cooled, filtered and concentrated by using rotary evaporator. The crystal was washed with ethanol and dried in a desiccator over activated silica gel. The ligands and their complexes were characterized ${ }^{1} \mathrm{H}-\mathrm{NMR}$ and ${ }^{13} \mathrm{C}-\mathrm{NMR}$, Infra-red spectroscopy, Magnetic susceptibility, UV-Visible spectroscopy and C, H, and $\mathrm{N}$ elemental analysis.

\section{Complexometric Titration of complexes}

$0.05 \mathrm{mM}$ of the metal- guanidinobenzimidazole complex $(\mathrm{GBM}) /$ guanidinophosphonate benzimidazole, (GPBM), was mixed with $5 \mathrm{ml}$ of concentrated nitric acid. The mixture was heated and evaporated to almost dryness on a hot plate. It was allowed to cool. Addition of little quantity of
The cooled solution was filtered and washed with 5 to $10 \mathrm{ml}$ of ethanol (Malek et al., 2011). The crude guanidinophosphonatebenzimidazole (8) was purified using column chromatography and nhexane as the solvent. The yield, melting point and other analytical dataare presented in Table 1.

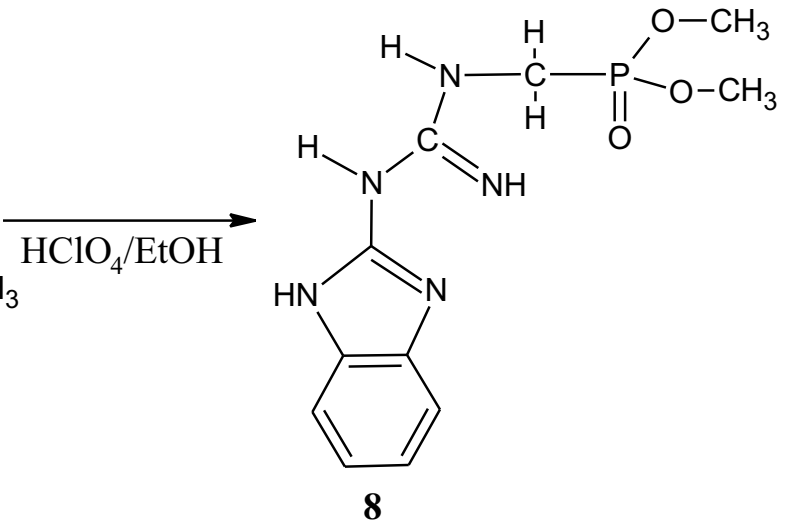

deionized distilled water was carried out three times and heated to almost dryness. It was allowed to cool and $10 \mathrm{ml}$ of deionized distilled water was added. The solution was transferred into a $50 \mathrm{ml}$ standard volumetric flask and made up to mark. 10 $\mathrm{ml}$ of the complex solution was pipetted into a 250 $\mathrm{ml}$ conical flask followed by addition of $4 \mathrm{ml}$ of $1 \mathrm{M}$ sodium hydroxide solution. Methyl thymol blue indicator was added and the solution was titrated with standardized EDTA in three replicates and average titre was calculated. At the end point, the colour changed from blue to grey. The molarity of the EDTA obtained when standardized with $0.01 \mathrm{M}(1.61 \mathrm{~g})$ of Zinc salt. This procedure was repeated for all the complexes.

Percentage metal composition in each of the complexes was therefore determined.

\section{RESULTS AND DISCUSSION}

Analytical data of Guanidinobenzimidazole, (GBM) and guanidinophosphonate benzimidazole, (GPBM) and the metal complexes.

The analytical data such as colours, percentage yields, the melting points and other characterization data of the ligands guanidinobenzimidazole, (GBM), guanidinophosphonatebenzimidazole, (GPBM) and their complexes are given in (Tables 1 and 2). 
Table 1: Analytical data of the ligands and the Complexes

\begin{tabular}{|l|l|l|l|l|l|}
\hline Compounds & Empirical formula & $\begin{array}{l}\text { Molecular } \\
\text { weight }\end{array}$ & Yield $(\%)$ & $\begin{array}{l}\text { Melting point } \\
\left({ }^{\circ} \mathrm{C}\right)\end{array}$ & Colour \\
\hline GBM & $\mathrm{C}_{8} \mathrm{H}_{9} \mathrm{~N}_{5}$ & 175.19 & 88 & $92-94$ & Yellow \\
\hline Fe- GBM & {$\left[\mathrm{Fe}\left(\mathrm{C}_{8} \mathrm{H}_{9} \mathrm{~N}_{5}\right)_{2}\right]$} & 406.225 & 84 & $127-129$ & Brown \\
\hline $\mathrm{Co}-\mathrm{GBM}$ & {$\left[\mathrm{Co}\left(\mathrm{C}_{8} \mathrm{H}_{9} \mathrm{~N}_{5}\right)_{2}\right]$} & 409.31 & 76 & $190-192$ & Brown \\
\hline $\mathrm{Ni}-\mathrm{GBM}$ & {$\left[\mathrm{Ni}\left(\mathrm{C}_{8} \mathrm{H}_{9} \mathrm{~N}_{5}\right)_{2}\right]$} & 409.07 & 78 & $147-149$ & Brown \\
\hline $\mathrm{Cu}-\mathrm{GBM}$ & {$\left[\mathrm{Cu}\left(\mathrm{C}_{8} \mathrm{H}_{9} \mathrm{~N}_{5}\right)_{2}\right]$} & 413.93 & 89 & $140-142$ & Green \\
\hline $\mathrm{Zn}-\mathrm{GBM}$ & {$\left[\mathrm{Cu}\left(\mathrm{C}_{8} \mathrm{H}_{9} \mathrm{~N}_{5}\right)_{2}\right]$} & 415.79 & 84 & $144-146$ & Orange \\
\hline GPBM & $\mathrm{C}_{11} \mathrm{H}_{16} \mathrm{~N}_{5} \mathrm{PO}_{3}$ & 297.25 & 89 & $139-141$ & Yellow \\
\hline Fe- GPBM & {$\left[\mathrm{Fe}\left(\mathrm{C}_{11} \mathrm{H}_{16} \mathrm{~N}_{5} \mathrm{PO}_{3}\right)_{2}\right]$} & 650.35 & 86 & $191-193$ & Brown \\
\hline $\mathrm{Co}-\mathrm{GPBM}$ & {$\left[\mathrm{Co}\left(\mathrm{C}_{11} \mathrm{H}_{16} \mathrm{~N}_{5} \mathrm{PO}_{3}\right)_{2}\right]$} & 653.43 & 78 & $196-198$ & Brown \\
\hline $\mathrm{Ni}-\mathrm{GPBM}$ & {$\left[\mathrm{Ni}\left(\mathrm{C}_{11} \mathrm{H}_{16} \mathrm{~N}_{5} \mathrm{PO}_{3}\right)_{2}\right]$} & 653.19 & 68 & $194-196$ & Brown \\
\hline $\mathrm{Cu}-\mathrm{GPBM}$ & {$\left[\mathrm{Cu}\left(\mathrm{C}_{11} \mathrm{H}_{16} \mathrm{~N}_{5} \mathrm{PO}_{3}\right)_{2}\right]$} & 658.05 & 75 & $192-194$ & Brown \\
\hline $\mathrm{Zn}-\mathrm{GPBM}$ & {$\left[\mathrm{Zn}\left(\mathrm{C}_{11} \mathrm{H}_{16} \mathrm{~N}_{5} \mathrm{PO}_{3}\right)_{2}\right]$} & 659.91 & 82 & $194-196$ & Pink \\
\hline
\end{tabular}

\section{C,H, N Analysis}

The CHN elemental Analysis of GBM and GBPMare presented in Table: 2

Table 2: C, H, N elemental Analysis of GBM and GPBM

\begin{tabular}{|l|l|l|l|}
\hline LIGANDS & \multicolumn{3}{|c|}{ Analysis Calculated (Found) } \\
\hline & $\% \mathrm{C}$ & $\% \mathrm{H}$ & $\% \mathrm{~N}$ \\
\hline GBM $\left(\mathrm{C}_{8} \mathrm{H}_{9} \mathrm{~N}_{5}\right)$ & 54.84 & 5.17 & 39.90 \\
& $(54.48)$ & $(5.15)$ & $(39.50)$ \\
\hline GBPM $\left(\mathrm{C}_{11} \mathrm{H}_{16} \mathrm{~N}_{5} \mathrm{PO}_{3}\right)$ & 46.10 & 6.43 & 22.35 \\
& $(46.08)$ & $(6.01)$ & $(22.30)$ \\
\hline
\end{tabular}

Percentage composition of the metals in the $\mathrm{Ni}(\mathrm{II}), \mathrm{Cu}(\mathrm{II})$ and $\mathrm{Zn}(\mathrm{II})$ and $\mathrm{L}$ for complexes

The results from calculations and the inferences from the percentage composition of the metals in the complexes suggest that ratio of the metal to ligands is $1: 2(\mathrm{M}: \mathrm{L})$ where $\mathrm{M}=\mathrm{Fe}(\mathrm{II}), \mathrm{Co}(\mathrm{II})$, guanidinobenzimidazole and guanidinophosphonatebenzimidazole. The prepared complexes were therefore found to have the general formulae $\left[\mathrm{ML}_{2}\right]$.

Table 3: Percentage compositionof metals in the complexes, the stoichiometry and the Probable Formulae.

\begin{tabular}{|l|c|c|c|}
\hline \multicolumn{1}{|c|}{ Compounds } & $\begin{array}{l}\text { \% Metal Found } \\
\text { (Calculated) }\end{array}$ & Stoichiometry & Probable Formula \\
\hline M- GBM & $13.32(13.74)$ & $1: 2$ & $\mathrm{Fe}(\mathrm{L})_{2}$ \\
\hline$\left[\mathrm{Fe}\left(\mathrm{C}_{8} \mathrm{H}_{9} \mathrm{~N}_{5}\right)_{2}\right]^{2+}$ & $1: 2$ & $\mathrm{Co}(\mathrm{L})_{2}$ \\
\hline$\left[\mathrm{Co}\left(\mathrm{C}_{8} \mathrm{H}_{9} \mathrm{~N}_{5}\right)_{2}\right]^{2+}$ & $14.54(14.40)$ & $1: 2$ & $\mathrm{Ni}(\mathrm{L})_{2}$ \\
\hline$\left[\mathrm{Ni}\left(\mathrm{C}_{8} \mathrm{H}_{9} \mathrm{~N}_{5}\right)_{2}\right]^{2+}$ & $14.48(14.35)$ & $1: 2$ & $\mathrm{Zn}(\mathrm{L})_{2}$ \\
\hline$\left[\mathrm{Cu}\left(\mathrm{C}_{8} \mathrm{H}_{9} \mathrm{~N}_{5}\right)_{2}\right]^{2+}$ & $15.41(15.35)$ & $1: 2$ & $\mathrm{Fe}(\mathrm{L})_{2}$ \\
\hline$\left[\mathrm{Zn}\left(\mathrm{C}_{8} \mathrm{H}_{9} \mathrm{~N}_{5}\right)_{2}\right]^{2+}$ & $15.91(15.72)$ & $1: 2$ & $\mathrm{Co}(\mathrm{L})_{2}$ \\
\hline $\mathbf{M}-\mathrm{GPBM}^{\mid}$ & $1: 2$ & $\mathrm{Ni}(\mathrm{L})_{2}$ \\
\hline$\left[\mathrm{Fe}\left(\mathrm{C}_{11} \mathrm{H}_{16} \mathrm{~N}_{5} \mathrm{PO}_{3}\right)_{2}\right]^{2+}$ & $8.58(8.59)$ & $1: 2$ & $\mathrm{Cu}(\mathrm{L})_{2}$ \\
\hline$\left[\mathrm{Co}\left(\mathrm{C}_{11} \mathrm{H}_{16} \mathrm{~N}_{5} \mathrm{PO}_{3}\right)_{2}\right]^{2+}$ & $9.16(9.02)$ & $1: 2$ & $\mathrm{Zn}(\mathrm{L})_{2}$ \\
\hline$\left[\mathrm{Ni}\left(\mathrm{C}_{11} \mathrm{H}_{16} \mathrm{~N}_{5} \mathrm{PO}_{3}\right)_{2}\right]^{2+}$ & $8.98(8.99)$ & $1: 2$ & \\
\hline$\left[\mathrm{Cu}\left(\mathrm{C}_{11} \mathrm{H}_{16} \mathrm{~N}_{5} \mathrm{PO}_{3}\right)_{2}\right]^{2+}$ & $9.65(9.66)$ & $10.00(9.91)$ &
\end{tabular}


Table 4: $\quad{ }^{1}$ H-NMR chemical shift $(\delta)$ of GBM and GPBM.

\begin{tabular}{|c|c|c|c|c|c|c|c|c|}
\hline $\mathbf{S} / \mathbf{N}$ & Ligands & $\begin{array}{l}\mathrm{CH} \\
\text { aromatic protons } \\
(\mathrm{ppm})\end{array}$ & $\begin{array}{l}\text { NH } \\
\text { protons } \\
\text { imidazo } \\
1 \\
\text { (ppm) }\end{array}$ & $\begin{array}{l}\text { N-H } \\
\text { protons } \\
\text { Exo } \\
\text { (ppm) }\end{array}$ & $\begin{array}{l}\mathrm{NH}_{2}, \\
\mathrm{C}=\mathrm{NH} \\
\text { protons } \\
\text { Exo } \\
\text { (ppm) }\end{array}$ & $\begin{array}{l}\mathrm{NH}, \\
\mathrm{C}=\mathrm{NH} \\
\text { protons } \\
\text { Exo } \\
\text { (ppm) }\end{array}$ & $\begin{array}{l}\text { P-C-H } \\
\text { proton } \\
(\mathrm{ppm})\end{array}$ & $\mathrm{PO}\left(\mathrm{OCH}_{3}\right)_{2}$ \\
\hline 1. & GBM & $7.00-7.30$ & $\begin{array}{l}6.80- \\
6.90\end{array}$ & $6.80-6.90$ & $6.15-6.40$ & & --- & --- \\
\hline 2. & GPBM & $7.00-7.90$ & $\begin{array}{l}6.00- \\
6.30\end{array}$ & $4.20-5.40$ & -- & $1.1-1.3$ & $\begin{array}{l}2.50- \\
2.80\end{array}$ & $3.20-4.20$ \\
\hline
\end{tabular}

Table $5:{ }^{13} \mathrm{C}-\mathrm{NMR}$ chemical shift $(\delta)$ of GBM, GPBM

\begin{tabular}{|l|l|l|l|l|l|l|l|}
\hline Compounds & $\mathrm{C}_{2}(\mathrm{ppm})$ & $\begin{array}{l}\mathrm{C}_{4}-\mathrm{C}_{7} \\
(\mathrm{ppm})\end{array}$ & $\begin{array}{l}\mathrm{C}_{5}-\mathrm{C}_{6} \\
(\mathrm{ppm})\end{array}$ & $\begin{array}{l}\mathrm{C}_{8}-\mathrm{C}_{9} \\
(\mathrm{ppm})\end{array}$ & $\begin{array}{l}\mathrm{C}_{11} \\
(\mathrm{ppm})\end{array}$ & $\mathrm{C}_{14}$ & $\mathrm{C}_{16}-\mathrm{C}_{17}$ \\
\hline $\mathrm{GBM}\left(\mathrm{C}_{8} \mathrm{H}_{9} \mathrm{~N}_{5}\right)$ & 155.35 & 112.00 & 119.62 & 138.22 & 185.28 & & \\
\hline $\mathrm{GPBM}\left(\mathrm{C}_{11} \mathrm{H}_{16} \mathrm{~N}_{5} \mathrm{PO}_{3}\right)$ & 150.83 & 111.75 & 131.61, & 129.42 & 172.63 & 49.03 & 60.95 \\
\hline
\end{tabular}
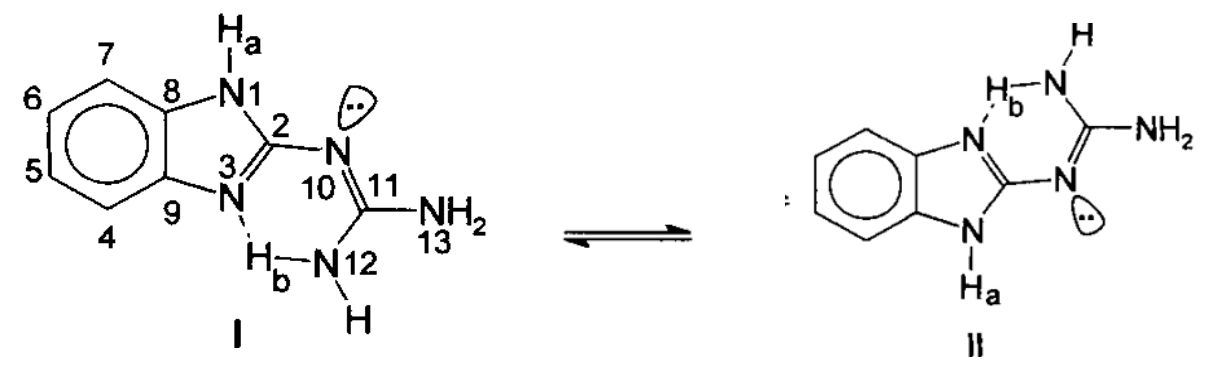

Scheme 1: The guanidine- benzimidazole structure.

\section{Guanidinobenzimidazole (GBM)}

A high yield of $88 \%$ of a yellow solid of GBM was obtained. It had a melting point range of 92 $94{ }^{\circ} \mathrm{C}$. The results from the elemental analysis were close to the expected values with $\% \mathrm{C}, \mathrm{H}, \mathrm{N}$ calculated being 54.84, 5.17, and 39.90 respectively while $\% \mathrm{C}, \mathrm{H}, \mathrm{N}$ of the product were $54.48,5.15$ and 39.50 respectively. In the UVVisible spectrum of guanidinobenzimidazole, (Figure 19), the band observed at $229 \mathrm{~nm}$ has been attributed to the absorption arising from the $\pi^{* \leftarrow}$ $\pi$ electronic transitions while the transition around $275 \mathrm{~nm}$ characterizes the $\pi^{*} \leftarrow n$ resulting from the lone pair of electrons (Khatiworaet al., 2012, Raoet al., 1964, Anderson et al., 2004). The band at $3255 \mathrm{~cm}^{-1}$ in the IR spectrum of GBM (Figure 7) is assigned to the $v(\mathrm{~N}-\mathrm{H})$ stretching frequency vibration. The vibration stretching frequencies of aromatic $\nu(\mathrm{C}-\mathrm{H})$ and $\nu(\mathrm{C}=\mathrm{C})$ were observed at $3055 \mathrm{~cm}^{-1}$ and about $1700 \mathrm{~cm}^{-1}$ respectively in the IR spectrum of GBM. The peaks at $1558 \mathrm{~cm}^{-1}$ and $1272 \mathrm{~cm}^{-1}$ in the spectrum of guanidinobenzimidazole are ascribed to $v(\mathrm{C}=\mathrm{N})$ imidazolic and $v(\mathrm{C}-\mathrm{N})$ vibration frequencies, respectively (Strivastava and Sen, 2008).

In the ${ }^{1} \mathrm{H}-\mathrm{NMR}$ spectra of the free guanidinobenzimidazole ligand (Figure 1), the chemical shift about $7.00-7.30$ ppm resonance is assigned to the benzene aromatic ring protons in the ligand (Sonmez, 2001). The resonance due to the imidazolic and exocyclic $\mathrm{NH}$ proton was observed at $6.80-6.90 \mathrm{ppm}$ while the terminal exocyclic $\mathrm{C}=\mathrm{NH}$ protons were observed upfield around 6.15 - 6.40 ppm (Lopez et al., 1997; Sonmez, 2001). The resonance due to the $\mathrm{NH}_{2}$ proton signal also appeared almost around the $6.15-6.40 \mathrm{ppm}$. From the ${ }^{13} \mathrm{C}-\mathrm{NMR}$ spectra, (Figure 3) recorded in DCOD shift the chemical shift at $185 \mathrm{ppm}$ is assigned to the resonance due to terminal carbon at position 11 (Scheme 1) of the guanidinobenzimidazole ligand (Padmaja et al., 2011). The signal at $155 \mathrm{ppm}$ indicates resonance peak for the imidazolic position C-2 while the signal chemical shift around $138 \mathrm{ppm}$ is ascribed to the resonance due to carbons at positions C-8 and $\mathrm{C}-9$ of the aromatic ring system. It has been stated in the literature that slight asymmetric 
coupling pattern occurs in aromatic ring (Andrade et al., 1997). However, the presence of protons contributed to the high intensities observed for the chemical shift values ascribed to the resonances due to carbons at positions 5 and 6 at $120 \mathrm{ppm}$ and carbons at positions 4 and 7 at 112 ppm (Andrade et al., 1997)

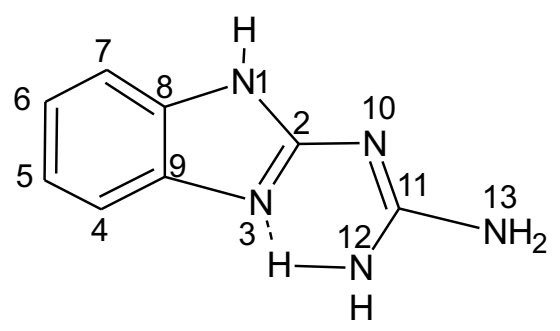

\section{Figure 5: Structure of Guanidino benzimidazole (GBM)}

\section{Guanidinophosphonatebenzimidazole (GPBM)}

The synthesis of GPBM gave a yellow solid with a yield of $89 \%$. It had a melting point range of 139 $-141^{\circ} \mathrm{C}$. The obtained results from the $\% \mathrm{C}, \mathrm{H}, \mathrm{N}$ elemental analysis, 46.08, 6.01, 22.30 respectively, were close to the calculated values, 46.10, 6.43 and 22.35 .

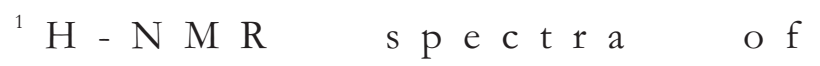
guanidinophosphonatebenzimidazole ligand (Figure 2), the aromatic protons of the benzene ring of the guanidinophosphonatebenzimidazole (Figure 6) showed a multiplet at chemical shift of 7.00-7.90 ppm (Reddy et al., 2007). The imidazolic N-H proton resonated at a chemical shift of $6.00-$ $6.30 \mathrm{ppm}$. The N-H next to the imidazolic ring of the guanidinophosphonatebenzimidazole ligand resonated at 4.20-5.40 ppm. Both the $\mathrm{C}=\mathrm{NH}$ and the methylene $\mathrm{N}-\mathrm{H}$ amine moiety of GPBM gave a signal around 1.1-1.3 ppm as multiplet due to electron delocalization and coupling effect with the methoxyl groups. The resonance due to the PC-H proton appeared as doublet at 2.50-2.80 ppm while the chemical shift around $3.20-4.20 \mathrm{ppm}$ is assigned to the resonance due to the two methoxyl groups of the GPBM ligand. The high intensities result from their positions in the same chemical environment (Reddy et al., 2007).

For the ${ }^{13} \mathrm{C}-\mathrm{NMR}$ spectrum, GPBM shows a chemical shift at $172 \mathrm{ppm}$ which is assigned to the resonance due to the carbon at position 11 (Table 5, Figure 4). This reflects the phosphorus coupling effect compared to the chemical shift at about 150 $\mathrm{ppm}$ assigned to the resonance due to the imidazolic carbon at position 2 of the GPBM ligand (Andrade et al., 1997, Reddy et al., 2007). The signal at $129 \mathrm{ppm}$ is attributed to the resonance due to the equivalent carbons at positions 8 and 9 of the aromatic ring system (Andrade et al., 1997). The signals at 131 and $111 \mathrm{ppm}$ are due to the resonance attributed to the equivalent $\mathrm{C}_{5}-\mathrm{C}_{6}$ and $\mathrm{C}_{4}-\mathrm{C}_{7}$ respectively (Padmaja et al., 2011). The chemical shift of the resonance due to the $\mathrm{PO}\left(\mathrm{OCH}_{3}\right)_{2}$ is observed around $60 \mathrm{ppm}$ while the methyl carbon with doublet character due to the coupling effect of the phosphorus are observed at the chemical shift of 49 ppm (Reddy et al., 2007).

In the UV visible spectrum of GPBM ligand, (Figure 20), the band at $260 \mathrm{~nm}$ has been attributed to the absorption arising from the $\pi^{* \leftarrow}$ $\pi$ electronic transitions while the transition around $281 \mathrm{~nm}$ characterizes the $\pi^{*} \leftarrow n$ resulting from the lone pair of electrons (Khatiworaet al., 2012, Raoet al., 1964, Anderson et al., 2004). The very strong band at $3379 \mathrm{~cm}^{-1}$ in the IR spectrum of GPBM (Figure 8) is assigned to the $v(\mathrm{~N}-\mathrm{H})$ stretching frequency vibration. The vibration stretching frequencies of aromatic $v(\mathrm{C}-\mathrm{H})$ and $v(\mathrm{C}=\mathrm{C})$ were observed at $3163 \mathrm{~cm}^{-1}$ and about $1651 \mathrm{~cm}^{-1}$ respectively in the spectrum of GPBM. The peaks at $1566 \mathrm{~cm}^{-1}$ and $1110 \mathrm{~cm}^{-1}$ in the spectrum of guanidinophosphonate benzimidazole are ascribed to $v(\mathrm{C}=\mathrm{N})$ imidazolic and $\nu(\mathrm{C}-\mathrm{N})$ vibration frequencies, respectively (Strivastava and Sen, 2008), while the $\nu(\mathrm{P}=\mathrm{O})$ gave the band at $1265 \mathrm{~cm}^{-1}$

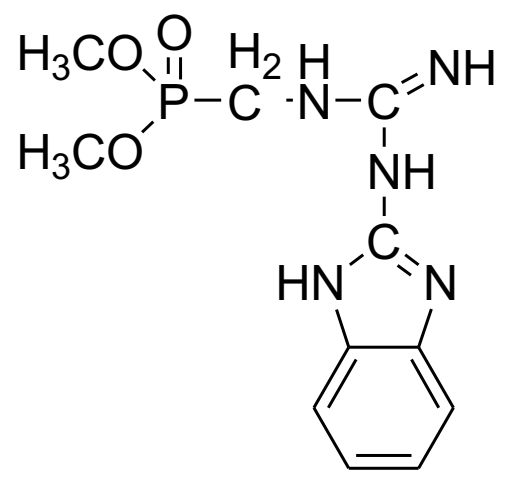

Figure 6: $\quad$ Structure of Guanidinophos phonatebenzimidazole (GPBM) 
CHARACTERIZATION OF THE METAL COMPLEXES

In order to study the binding mode of the guanidinobenzimidazole, (GBM) and guanidinophosphonatebenzimidazole, (GPBM) with the metal ions, comparisons of the IR spectra of the free ligands (Figures 7 and 8) and those of their metal complexes, (Figures 9-13) were made. The major characteristic bands in the IR spectra of the ligands and the ten metal complexes are listed in Table 6.

Analyses and comparisons of the electronic spectral data of the ligands, GBM, GPBM and their metal complexes indicated the participation of the nitrogen atoms of the guanidino benzimidazole ligand in the coordination of the ligands to the metal ions.

The vibration stretching frequencies of aromatic $\nu(\mathrm{C}-\mathrm{H})$ and $\nu(\mathrm{C}=\mathrm{C})$ observed at $3055 \mathrm{~cm}^{-1}$ and about $1700 \mathrm{~cm}^{-1}$ respectively in the spectrum of GBM, remain almost constant in the spectra of the metal complexes. This suggests the noninvolvement of the proton $v(\mathrm{C}-\mathrm{H})$ and the $v(\mathrm{C}=\mathrm{C})$ in the complex formation. This is not unexpected.

The shifts in the position of the $v(\mathrm{P}=\mathrm{O})$ absorption band of the phosphonate moiety in the guanidinophosphonatebenzimidazole, (GPBM) ligand from $1265 \mathrm{~cm}^{-1}$ in the free ligand to $1141 \mathrm{~cm}^{-1}-1200 \mathrm{~cm}^{-1}$ in the metal complexes suggested the involvement of the $\mathrm{P}=\mathrm{O}$ together with the nitrogen atoms in the coordination of the metal ions to the guanidinophosphonate benzimidazole, (GPBM) ligand. The lowest shift occurred for the cobalt complex, Co(II)-GPBM.

The broadness of the bands in the region 3600 $3200 \mathrm{~cm}^{-1}$ in the spectra of the metal complexes as compared to that of the ligand suggest the presence of coordinated water molecule(s),( Singh, et al, 2002).

\section{Fe(II)-GBM and Fe(II)-GPBM}

Both Fe(II)-GBM and Fe(II)-GPBM complexes are brownish in colour with melting points of 127$129^{\circ} \mathrm{C}$ and $191-193{ }^{\circ} \mathrm{C}$ and $\%$ yield of 84 and $86 \%$ respectively. The $\%$ metal found and the values calculated respectively were $13.32 \%$ and $13.75 \%$ for Fe(II)-GBM and 8.58 and $8.59 \%$ for Fe(II)GPBM.

\section{FTIR Spectra.}

The shift from $3255 \mathrm{~cm}^{-1}$ band to $3332 \mathrm{~cm}^{-1}$ in $\mathrm{Fe}(\mathrm{II})-\mathrm{GBM}$, (Figure 9) indicated the involvement of the amine nitrogen in the coordination with the metalion, (Bakir et al., 2013, Anitha et al., 2011, Andrade et al.,1997). The shifts of the $1558 \mathrm{~cm}^{-1}$ and $1272 \mathrm{~cm}^{-1}$ in the spectrum of guanidinobenzimidazole ascribed to $v(\mathrm{C}=\mathrm{N})$ imidazolic and $v(\mathrm{C}-\mathrm{N})$ vibration frequencies, respectively to $1481 \mathrm{~cm}^{-1}$ and $1211 \mathrm{~cm}^{-1}$ in Fe(II)GBM further indicated the participation of the imidazolic nitrogen atom and one of the guanidine nitrogen in the coordination of GBM to the metal ion, (Strivastava and Sen, 2008).

The appearance of new weak band at $532 \mathrm{~cm}^{-1}$ due to M-N bond is suggestive of the coordination of the metal ion to the GBM.

For, (Fe-GPBM), (Figure 14), the strong band at $3379 \mathrm{~cm}^{-1}$ in the GPBM ligand due to the $\nu(\mathrm{N}-\mathrm{H})$ stretching frequency vibration of the amine moiety (Reddy et al., 2007) shifted to $3186 \mathrm{~cm}^{-1}$ in Fe(II)-GPBM.

The lowering of the vibration frequenciessuggests complexation of the guanidinophos phonatebenzimidazole to the metal ion through the nitrogen atom, (Yadav et al., 2011 and Bakir et al, 2013).

The strong absorption band at $1566 \mathrm{~cm}^{-1}$ characteristic of the $v(\mathrm{C}=\mathrm{N})$ stretching vibration shifted to $1527 \mathrm{~cm}^{-1}$ in $\mathrm{Fe}(\mathrm{II})-\mathrm{GPBM}$ while the peak at $1110 \mathrm{~cm}^{-1}$. in GPBM due to $v(\mathrm{C}-\mathrm{N})$, shifted to $1041 \mathrm{~cm}^{-1}$ in $\mathrm{Fe}(\mathrm{II})-\mathrm{GPBM}$. These further confirmed the involvement of the nitrogenatom in coordination of the metal ion to the ligand, (Osowole, 2012).

The new band at $532 \mathrm{~cm}^{-1}$ in the spectrum of the metal complex is indicative of $\nu(\mathrm{M}-\mathrm{N})$ vibration frequency, (Padmajaet al, 2011).

The shift in the position of thev $(\mathrm{P}=\mathrm{O})$ absorption band from $1265 \mathrm{~cm}^{-1}$ in the free ligand to $1188 \mathrm{~cm}^{-1}$ 
in $\mathrm{Fe}(\mathrm{II})-\mathrm{GPBM}$ suggests that the $\mathrm{P}=\mathrm{O}$ is probably involved in the coordination of the metal ion to the GPBM ligand. This is supported by the appearance of $\mathrm{M}-\mathrm{O}$ band at $650 \mathrm{~cm}^{-1}$, (Ferrero, 1971).

UV-Visible and Magnetic susceptibility data The electronic spectrum of the Fe(II)-GBM complex gave absorption peak of high intensities at $287 \mathrm{~nm}$ (Figure 21). This is related to ligand metal charge transfer (Bakir et al.,2013). The absence of peak in the visible region indicated that there was probably no (d-d) transition. However, the magnetic moment value of 2.06 B.M for the $\mathrm{Fe}(\mathrm{II})$ complex falls within the range for distorted octahedral geometry (Padmaja et al., 2011).

The electronic spectrum of the Fe(II)-GPBM showed absorption band around $560 \mathrm{~nm}$ (Figure 26) which could be attributed to $^{3} \mathrm{~T}_{2} \mathrm{~g} \rightarrow \mathrm{Eg}$ presumably arising from the octahedral geometry orientation, (Konig, E, et al, 1985), in agreement with the magnetic moment of 2.02 B.M for this complex, (Anitha et al.,2011).

\section{Co(II)-GBM and Co(II)-GPBM}

Co(II)-GBM and Co(II)-GPBM complexes are brownish in colour with melting points of 190 $192{ }^{\circ} \mathrm{C}$ and $196-198{ }^{\circ} \mathrm{C}$ and $\%$ yield of 76 and $78 \%$ respectively. The $\%$ metal found and the values calculated respectively were $14.40 \%$ and $14.54 \%$ for Co(II)-GBM and 9.02 and $9.16 \%$ for Co(II)GPBM.

\section{FTIR Spectra.}

The shift from $3255 \mathrm{~cm}^{-1}$ band to very broad band from 3400-3209 $\mathrm{cm}^{-1}$ in Co(II)-GBM, (Figure 10) indicated the involvement of the amine nitrogen in the coordination with the metal ion, (Bakir et al., 2013, Anitha et al., 2011, Andrade et al.,1997) as well as the incorporation of water molecules in the coordination sphere, (Singh, et al, 2002).The shifts of the $1558 \mathrm{~cm}^{-1}$ and $1272 \mathrm{~cm}^{-1}$ in the spectrum of guanidinobenzimidazole ascribed to $v(\mathrm{C}=\mathrm{N})$ imidazolic and $v(\mathrm{C}-\mathrm{N})$ vibration frequencies, respectively to $1481 \mathrm{~cm}^{-1}$ and $1211 \mathrm{~cm}^{-1}$ in $\mathrm{Co}(\mathrm{II})-$ GBM further indicated the participation of the nitrogen atoms in the coordination of GBM to the metalion, (Strivastava and Sen, 2008).
The appearance of new weak band at $578 \mathrm{~cm}^{-1}$ suggests the presence of an $\mathrm{M}-\mathrm{N}$ bond.

For, (Co-GPBM), (Figure 15), the strong band at $3379 \mathrm{~cm}^{-1}$ in the GPBM ligand due to the $\nu(\mathrm{N}-\mathrm{H})$ stretching frequency vibration of the amine moiety (Reddy et al., 2007) shifted into a very broad in the region $3500-3300 \mathrm{~cm}^{-1}$ in $\mathrm{Co}(\mathrm{II})-$ GPBM.

The lowering of the vibration frequencies alsosuggests complexation of the guanidinophosphonatebenzimidazole to the metal ion through the nitrogen atom, (Yadav et al., 2011 and Bakir et al2013).

The strong absorption band at $1566 \mathrm{~cm}^{-1}$ due to $v(\mathrm{C}=\mathrm{N})$ stretching vibration shifted to $1527 \mathrm{~cm}^{-1}$ while the peak at $1110 \mathrm{~cm}^{-1}$.in GPBM due to $\nu(C-$ $\mathrm{N})$, shifted to $1072 \mathrm{~cm}^{-1}$. The new band at $555 \mathrm{~cm}^{-1}$ in the spectrum of the metal complex is indicative of $\nu(\mathrm{M}-\mathrm{N})$ vibration frequency, (Padmajaet al, 2011).

The position of thev $(\mathrm{P}=\mathrm{O})$ absorption band shifted from $1265 \mathrm{~cm}^{-1}$ in the free ligand to 1141 $\mathrm{cm}^{-1}$ in Co(II)-GPBM. This also suggests the involvement of $\mathrm{P}=\mathrm{O}$ in the coordination of the metal ion to the GPBM ligand. This is supported by the appearance of $\mathrm{M}-\mathrm{O}$ band at $624 \mathrm{~cm}^{-1}$

\section{UV-Visible and Magnetic susceptibility data}

The electronic spectrum of the Co(II)-GBM complex, (Figure 22) gave an absorption peakat $530 \mathrm{~nm}$. This must have resulted from the $\mathrm{d}-\mathrm{d}$ transition of the type ${ }^{4 \mathrm{~T} 1 \mathrm{~g}}(\mathrm{~F}) \rightarrow{ }^{4} \mathrm{~T}_{2 \mathrm{~g}}(\mathrm{~F})$. The Co(II)GBM also has magnetic susceptibility value of 1.78 B.M which lies within the range expected for octahedral geometry (Anderson et al., 2004).

The electronic absorption spectrum of the Co(II)-guanidinophosphonatebenzimidazole complex shows a $560 \mathrm{~nm}$ signal (Figure 27). This also corresponds to ${ }^{4} \mathrm{~T}_{1} \mathrm{~g}(\mathrm{~F}) \stackrel{{ }^{4} \mathrm{~T}}{\mathrm{~T}} \mathrm{2g}(\mathrm{F})$ transition.

\section{Ni(II)-GBM and Ni(II)-GPBM}

Both Ni(II)-GBM and Ni(II)-GPBM complexes are brownish in colour with melting points of $147-148^{\circ} \mathrm{C}$ and $194-196^{\circ} \mathrm{C}$ and \% yield of 78 and $68 \%$ respectively. The $\%$ metal found and the values calculated respectively were $14.35 \%$ and 
$14.48 \%$ for $\mathrm{Ni}(\mathrm{II})-\mathrm{GBM}$ and 8.98 and $8.99 \%$ for Ni(II)-GPBM.

\section{FTIR Spectra.}

The shift from $3255 \mathrm{~cm}^{-1}$ band to a broad from 3200 to $3340 \mathrm{~cm}^{-1}$ in Ni(II)-GBM, (Figure 11) indicated the involvement of the amine nitrogen and water molecules in the coordination with the metal ion, (Bakir et al., 2013, Anitha et al., 2011, Andrade et al.,1997). The shifts of the $1558 \mathrm{~cm}^{-1}$ and $1272 \mathrm{~cm}^{-1}$ in the spectrum of guanidinobenzimidazole ascribed to $v(\mathrm{C}=\mathrm{N})$ imidazolic and $v(\mathrm{C}-\mathrm{N})$ vibration frequencies, respectively to $1481 \mathrm{~cm}^{-1}$ and $1211 \mathrm{~cm}^{-1}$ in $\mathrm{Ni}(\mathrm{II})$ GBM further indicated the participation of these nitrogen atoms in the coordination of GBM to the metal ion, (Strivastava and Sen, 2008).

The appearance of new weak band at $540 \mathrm{~cm}^{-1}$ $\nu(\mathrm{M}-\mathrm{N})$ for confirms the coordination of the metal ion to the nitrogen atom.

For, (Ni-GPBM), (Figure16 ), the strong band at $3379 \mathrm{~cm}^{-1}$ in the GPBM ligand due to the $v(\mathrm{~N}-\mathrm{H})$ stretching frequency vibration of the amine moiety (Reddy et al., 2007) has been replaced by a very broad band $3000-3400 \mathrm{~cm}^{-1}$.

The strong absorption band at $1566 \mathrm{~cm}^{-1}$ in the ligand has shifted to $1519 \mathrm{~cm}^{-1}$. While the peak at $1110 \mathrm{~cm}^{-1}$ in GPBM due to $v(\mathrm{C}-\mathrm{N})$, shifted to $1056 \mathrm{~cm}^{-1}$ in Ni(II)-GPBM. These further confirmed the involvement of the nitrogen atom in the coordination, (Osowole, 2012).

The new band at $547 \mathrm{~cm}^{-1}$ in Ni(II)-GPBM spectrum can be attributed to the $v(\mathrm{M}-\mathrm{N})$ vibration frequency, (Padmaja et al, 2011).

The shift in the position of the $v(\mathrm{P}=\mathrm{O})$ absorption band from $1265 \mathrm{~cm}^{-1}$ in the free ligand to $1164 \mathrm{~cm}^{-1}$ in Ni(II)-GPBM suggests the coordination of the $\mathrm{P}=\mathrm{O}$ to the metal ion. This is supported by the appearance of $\mathrm{M}-\mathrm{O}$ band at $600 \mathrm{~cm}^{-1}$

UV-Visible and Magnetic susceptibility data The electronic spectral band of $\mathrm{Ni}(\mathrm{II})-\mathrm{GBM}$ complex (Figure 23) gave a band with the peak at $650 \mathrm{~nm}$ and it is attributable to the electronic transition to ${ }^{3} \mathrm{~A}_{2 \mathrm{~g}}(\mathrm{~F}) \rightarrow{ }^{3} \mathrm{~T}_{1 \mathrm{~g}}(\mathrm{~F})$. The magnetic moment was found to be 3.10 B.M, a value within the range of 2.9-3.3 B.M for octahedral complexes of $\mathrm{Ni}(\mathrm{II})$, thus suggesting octahedral geometry (Bakir et al., 2013).

The Ni(II)-GPBM complex exhibits a spectral band at $321 \mathrm{~nm}$ which may likely be due to ligand metal charge transfer. The value of magnetic moment for $\mathrm{Ni}$ (II)-GPBM is 3.02 B.M which is within the predictable range for an octahedral geometry (Khatiwora et al., 2012).

\section{$\mathrm{Cu}$ (II)-GBM and $\mathrm{Cu}$ (II)-GPBM}

$\mathrm{Cu}$ (II)-GBM is greenish while $\mathrm{Co}(\mathrm{II})-\mathrm{GPBM}$ is brownish in colour. Melting points are $140-142{ }^{\circ} \mathrm{C}$ and $192-194{ }^{\circ} \mathrm{C}$ respectively. The $\%$ yields are 89 and $75 \%$ respectively. The $\%$ metal found and the values calculated respectively were $15.35 \%$ and $15.41 \%$ for $\mathrm{Cu}(\mathrm{II})-\mathrm{GBM}$ and 9.65 and $8.66 \%$ for $\mathrm{Cu}(\mathrm{II})-\mathrm{GPBM}$.

FTIR Spectra. The shift from $3255 \mathrm{~cm}-1$ band to a broad band from 3200 to $3340 \mathrm{~cm}-1$ in Ni(II)-GBM, (Figure 12). This also suggests the involvement of the amine nitrogen and water molecules in the coordination with the metal ion, (Bakir et al., 2013, Anitha et al., 2011, Andrade et al., 1997). The shifts of the $1558 \mathrm{~cm}^{-1}$ and $1272 \mathrm{~cm}^{-1}$ bands in the spectrum of guanidinobenzimidazole ascribed to $v(\mathrm{C}=\mathrm{N})$ imidazolic and $\nu(\mathrm{C}-\mathrm{N})$ vibration frequencies, respectively to $1490 \mathrm{~cm}^{-1}$ and $1211 \mathrm{~cm}^{-1}$ in $\mathrm{Cu}(\mathrm{II})-$ GBM further indicated the participation of the nitrogen atoms in the coordination of GBM to the metal ion, (Strivastava and Sen, 2008).

The appearance of new weak band at $524 \mathrm{~cm}^{-1}$ is indicative of $(\mathrm{M}-\mathrm{N})$ bond and confirms the coordination of the metal ion to through the nitrogen atom in the GBM.

For, (Cu(II)-GPBM), (Figure 17 ), the strong band at $3379 \mathrm{~cm}^{-1}$ in the GPBM ligand due to the $v(\mathrm{~N}-\mathrm{H})$ stretching frequency vibration of the amine moiety (Reddy et al., 2007) gave a very broad band $3000-3500 \mathrm{~cm}^{-1}$ in $\mathrm{Cu}(\mathrm{II})-\mathrm{GPBM}$. Thissuggests complexation of the guanidinophosphonatebenzimidazole to the metal ion through the nitrogen atom, (Yadav et al., 
2011 and Bakir et al, 2013) and involvement of the water molecules.

The strong absorption band at $1566 \mathrm{~cm}^{-1}$ characteristic of the $\nu(C=N)$ stretching vibration is also shifted to $1527 \mathrm{~cm}^{-1}$ in $\mathrm{Cu}(\mathrm{II})-\mathrm{GPBM}$ while the peak at $1110 \mathrm{~cm}^{-1}$.in GPBM due to $\nu(\mathrm{C}-\mathrm{N})$, shifted to $1050 \mathrm{~cm}^{-1}$. These further confirmed the involvement of the nitrogen atom in coordination of the metal ion to the ligand, (Osowole, 2012).

The new band at $501 \mathrm{~cm}^{-1}$ in the spectrum of the metal complex is indicative of $\nu(\mathrm{M}-\mathrm{N})$ vibration frequency, (Padmajaetal, 2011).

The shift in the position of thev $(\mathrm{P}=\mathrm{O})$ absorption band from $1265 \mathrm{~cm}^{-1}$ in the free ligand to $1200 \mathrm{~cm}^{-1}$ in $\mathrm{Cu}(\mathrm{II})-\mathrm{GPBM}$ suggests that the $\mathrm{P}=\mathrm{O}$ is also involved in the coordination to the metal ion. The appearance of a band at about $620 \mathrm{~cm}^{-1}$ is likely due to an $\mathrm{M}-\mathrm{O}$ band.

\section{UV-Visible and Magnetic susceptibility data}

The guanidinobenzimidazole-Cu(II)-GBM complex has a peak at $350 \mathrm{~nm}$ (Figure24 .). This is likely due to ligand metal charge transfer. However the observed magnetic susceptibility of 2.08 B.M (Table 7) is within the range expected for distorted octahedral geometry (Padmaja et al., 2011).

The electronic absorption spectral band at $680 \mathrm{~nm}$ for the $\mathrm{Cu}(\mathrm{II})-\mathrm{GPBM}$ complex (Figure 29) is assigned to ${ }^{2} \mathrm{Eg}-{ }^{2} \mathrm{~T}_{2} \mathrm{~g}$ transition. The transition is in agreement with the magnetic susceptibility result of 2.01B.M suggesting distorted octahedral geometry for the $\mathrm{Cu}(\mathrm{II})-\mathrm{GPBM}$ complex.

The electronic absorption spectral band at $680 \mathrm{~nm}$ for the $\mathrm{Cu}$ (II)-GPBM complex (Figure 29) is assigned to ${ }^{2} \mathrm{Eg} \rightarrow{ }^{2} \mathrm{~T}_{2} \mathrm{~g}$ transition. The transition is in agreement with the magnetic susceptibility result of 2.01B.M suggesting distorted octahedral geometry for the $\mathrm{Cu}(\mathrm{II})-\mathrm{GPBM}$ complex.

\section{$\mathrm{Zn}$ (II)-GBM and $\mathrm{Zn}$ (II)-GBM}

$\mathrm{Zn}(\mathrm{II})-\mathrm{GBM}$ is orange in colour while $\mathrm{Zn}(\mathrm{II})$ GPBM complex is pink. The melting points are $144-146{ }^{\circ} \mathrm{C}$ and $194-196{ }^{\circ} \mathrm{C}$ and $\%$ yields were 84 and $82 \%$ respectively. The $\%$ metal found and the values calculated respectively were $15.91 \%$ and
$15.72 \%$ for $\mathrm{Zn}(\mathrm{II})-\mathrm{GBM}$ and $10.00 \%$ and $9.91 \%$ for $\mathrm{Zn}(\mathrm{II})-\mathrm{GPBM}$.

\section{FTIR Spectra.}

There was a shift from the slightly broad band at about $3200-3400 \mathrm{~cm}^{-1}$ in the GBM ligand to a broad band in the region $3200-3332 \mathrm{~cm}^{-1}$ in $\mathrm{Zn}$ (II)GBM, (Figure 13). This as explained for the other complexes are due to the involvement of the amine nitrogen and water molecules from the solvent coordinating to the metal ion, (Bakir et al., 2013, Anitha et al., 2011, Andrade et al.,1997). The $1558 \mathrm{~cm}^{-1}$ and $1272 \mathrm{~cm}^{-1}$ bands in the spectrum of guanidinobenzimidazole ligand also shifted to $1448 \mathrm{~cm}^{-1}$ and $1118 \mathrm{~cm}^{-1}$. These further indicated the participation of the nitrogen atoms in the coordination, (Strivastava and Sen, 2008).

The appearance of new band at $532 \mathrm{~cm}^{-1}$ is suggestive of an $\nu(\mathrm{M}-\mathrm{N})$ bond.

For, (Zn-GPBM), (Figure18), the strong band at $3379 \mathrm{~cm}^{-1}$ in the GPBM ligand due to the $\nu(\mathrm{N}-\mathrm{H})$ stretching frequency vibration of the amine moiety (Reddy et al., 2007) shifted to a very broad band, $3000-3200 \mathrm{~cm}^{-1}$ in $\mathrm{Zn}(\mathrm{II})-\mathrm{GPBM}$.

The change in the stretching frequenciessuggests complexation of the guanidinophosphonate benzimidazole to the metal ion through the nitrogen atom, (Yadav et al., 2011 and Bakir et al 2013) and involvement of the water molecules.

Absorption band at $1566 \mathrm{~cm}^{-1}$ characteristic of the $\checkmark(\mathrm{C}=\mathrm{N})$ stretching vibration shifted to $1519 \mathrm{~cm}^{-1}$ while the peak at $1110 \mathrm{~cm}^{-1}$.in GPBM due to $\nu(C-$ $\mathrm{N})$, shifted to $1056 \mathrm{~cm}^{-1}$. These further confirmed the involvement of the nitrogenatom, (Osowole, 2012).

The new band at $447 \mathrm{~cm}^{-1}$ in the spectrum of the metal complex is indicative of $v(\mathrm{M}-\mathrm{N})$ vibration frequency, (Padmajaet al, 2011).

The shift in the position of the $(\mathrm{P}=\mathrm{O})$ absorption band from $1265 \mathrm{~cm}^{-1}$ in the free ligand to $1200 \mathrm{~cm}^{-1}$ suggests that the $\mathrm{P}=\mathrm{O}$ is most likely to be involved in the coordination of the metal ion to the GPBM ligand. This is supported by the appearance of MO band at about $650 \mathrm{~cm}^{-1}$ 
UV-Visible and Magnetic susceptibility data

The electronic absorption spectrum for the $\mathrm{Zn}(\mathrm{II})-\mathrm{GBM}$ complex (Figure 25.) presented a diamagnetic behaviour as a consequence of its $\mathrm{d}^{10}$ electronic configuration. This is supported by the zero value for the magnetic moment. This is not unexpected.

For the $\mathrm{Zn}(\mathrm{II})-\mathrm{GPBM}$ complex, the transition at $330 \mathrm{~nm}$ in the electronic absorption spectrum (Figure 30) is most likely due to ligand metal charge transfer.

Table 6: Selected IR bands $\left(\mathrm{cm}^{-1}\right)$ of GBM, GPBM and their metal complexes

\begin{tabular}{|c|c|c|c|c|c|c|c|c|c|}
\hline $\mathrm{S} / \mathrm{N}$ & L/M-L & m & $v(\mathrm{C}-\mathrm{H})$ & $v(C=C)$ & $v(\mathrm{C}=\mathrm{N})$ & $v(\mathrm{C}-\mathrm{N})$ & $v(\mathrm{P}=\mathrm{O})$ & $v(\mathrm{M}-\mathrm{N})$ & $v(\mathrm{M}-0)$ \\
\hline 1 & GBM & 3255 & 3055 & 1700 & 1558 & 1272 & --- & ---- & ---- \\
\hline 2 & $\mathrm{Fe}-\mathrm{GBM}$ & $\begin{array}{l}3500- \\
3332 \\
\text { br } \\
\end{array}$ & 3054 & 1697 & 1481 & 1211 & --- & 532 & ----- \\
\hline 3 & $\mathrm{Co}-\mathrm{GBM}$ & $\begin{array}{l}3400- \\
3209\end{array}$ & 3065 & 1697 & 1481 & 1211 & $\begin{array}{l}--- \\
\end{array}$ & 578 & ----- \\
\hline 4 & $\mathrm{Ni}-\mathrm{GBM}$ & $\begin{array}{l}3400- \\
3340\end{array}$ & 3055 & 1697 & 1481 & 1211 & --- & 540 & ----- \\
\hline 5 & $\mathrm{Cu}-\mathrm{GBM}$ & $\begin{array}{l}3500- \\
3379\end{array}$ & 3200 & 1689 & 1490 & 1211 & --- & 524 & $\begin{array}{l}----- \\
\end{array}$ \\
\hline 6 & $\mathrm{Zn}-\mathrm{GBM}$ & $\begin{array}{l}3400- \\
3332 \\
\text { br }\end{array}$ & 3209 & 1681 & 1448 & 1118 & --- & 532 & ----- \\
\hline 7 & GPBM & 3379 v.s & 3163 & 1651 & 1566 & 1110 & 1265 & ----- & ------ \\
\hline 8 & Fe-GPBM & $\begin{array}{r}3400- \\
3186 \text { br }\end{array}$ & 3093 & 1658 & 1527 & 1041 & 1188 & 532 & 650 \\
\hline 9 & $\begin{array}{c}\mathrm{Co}- \\
\text { GPBM }\end{array}$ & $\begin{array}{l}3500- \\
3000 \text { br }\end{array}$ & 3093 & 1658 & 1527 & 1072 & 1141 & 555 & 624 \\
\hline 10 & $\begin{array}{c}\mathrm{Ni}- \\
\text { GPBM }\end{array}$ & $\begin{array}{l}3400- \\
3000 \\
\text { br }\end{array}$ & 3039 & 1658 & 1519 & 1056 & 1164 & 547 & 600 \\
\hline 11 & $\begin{array}{c}\mathrm{Cu}- \\
\text { GPBM }\end{array}$ & $\begin{array}{c}3500- \\
3000 \mathrm{br}\end{array}$ & 2939 & 1658 & 1527 & 1050 & 1200 & 501 & 620 \\
\hline 12 & $\begin{array}{c}\mathrm{Zn-} \\
\text { GPBM }\end{array}$ & $\begin{array}{l}3260- \\
3000 \\
\text { br. }\end{array}$ & 2962 & 1705 & 1519 & 1056 & 1200 & 447 & 650 \\
\hline
\end{tabular}


Table 7: UV-Visible electronic spectra data and magnetic susceptibility values of GBM, GPBM and their metal complexes.

\begin{tabular}{|c|c|c|c|c|}
\hline \multirow[t]{2}{*}{ Compounds } & \multicolumn{2}{|r|}{ UV-Visible Spectra } & $\begin{array}{l}\text { Magnetic } \\
\text { Moment } \\
\mu \text { eff(B.M) }\end{array}$ & Proposed geometry \\
\hline & $\begin{array}{l}\text { Absorption } \\
(\mathrm{nm})\end{array}$ & Transition & & \\
\hline $\mathrm{C}_{8} \mathrm{H}_{9} \mathrm{~N}_{5}$ & 229,275 & $\pi \rightarrow \pi^{*}, \mathrm{n} \rightarrow \pi^{*}$ & |- & \\
\hline$\left[\mathrm{Fe}\left(\mathrm{C}_{8} \mathrm{H}_{9} \mathrm{~N}_{5}\right)_{2}\right]$ & 287 & LMCT & 2.06 & Octahedral \\
\hline$\left[\mathrm{Co}\left(\mathrm{C}_{8} \mathrm{H}_{9} \mathrm{~N}_{5}\right)_{2}\right]$ & 530 & $\begin{array}{c}{ }^{4} \mathrm{~T} \\
2 \mathrm{~g}(\mathrm{~F})\end{array}$ & 1.78 & $\begin{array}{l}\text { Octahedral/ } \\
\text { distorted Octahedral }\end{array}$ \\
\hline$\left[\mathrm{Ni}\left(\mathrm{C}_{8} \mathrm{H}_{9} \mathrm{~N}_{5}\right)_{2}\right]$ & 650 & ${ }^{3} \mathrm{~A}_{2 g}(\mathrm{~F}) \rightarrow{ }^{3} \mathrm{~T}_{1 g}(\mathrm{~F})$ & 3.10 & $\begin{array}{l}\text { Octahedral/ } \\
\text { distorted Octahedral }\end{array}$ \\
\hline$\left[\mathrm{Cu}\left(\mathrm{C}_{8} \mathrm{H}_{9} \mathrm{~N}_{5}\right)_{2}\right]$ & 350 & LM CT & 2.08 & Distorted Octahedral \\
\hline$\left[\mathrm{Zn}\left(\mathrm{C}_{8} \mathrm{H}_{9} \mathrm{~N}_{5}\right)_{2}\right]$ & 274 & LMCT & 0 & $\begin{array}{l}\text { Octahedral/ } \\
\text { distorted Octahedral }\end{array}$ \\
\hline $\mathrm{C}_{11} \mathrm{H}_{16} \mathrm{~N}_{5} \mathrm{PO}_{3}$ & 260,281 & $\pi \rightarrow \pi^{*}, \mathrm{n} \rightarrow \pi^{*}$ & - & \\
\hline$\left[\mathrm{Fe}\left(\mathrm{C}_{11} \mathrm{H}_{16} \mathrm{~N}_{5} \mathrm{PO}_{3}\right)_{2}\right]$ & 560 & ${ }^{3} \mathrm{~T}_{2} \mathrm{~g} \rightarrow \mathrm{Eg}$ & 2.02 & $\begin{array}{l}\text { Octahedral/distorted } \\
\text { Octahedral }\end{array}$ \\
\hline$\left[\mathrm{Co}\left(\mathrm{C}_{11} \mathrm{H}_{16} \mathrm{~N}_{5} \mathrm{PO}_{3}\right)_{2}\right]$ & 560 & $\begin{array}{l}\quad{ }^{4} \mathrm{~T}_{1} \mathrm{~g}(\mathrm{~F}) \rightarrow \\
{ }^{4} \mathrm{~T}_{2} \mathrm{~g}(\mathrm{~F}),\end{array}$ & 1.79 & $\begin{array}{l}\text { Octahedral/ } \\
\text { distorted Octahedral }\end{array}$ \\
\hline$\left[\mathrm{Ni}\left(\mathrm{C}_{11} \mathrm{H}_{16} \mathrm{~N}_{5} \mathrm{PO}_{3}\right)_{2}\right]$ & 321 & LM CT & 3.02 & $\begin{array}{l}\text { Octahedral/ } \\
\text { distorted Octahedral }\end{array}$ \\
\hline$\left[\mathrm{Cu}\left(\mathrm{C}_{11} \mathrm{H}_{16} \mathrm{~N}_{5} \mathrm{PO}_{3}\right)_{2}\right]$ & 680 & ${ }^{2} \mathrm{Eg} \rightarrow{ }^{2} \mathrm{~T}_{2} g$ & 2.01 & Distorted Octahedral \\
\hline$\left[\mathrm{Zn}\left(\mathrm{C}_{11} \mathrm{H}_{16} \mathrm{~N}_{5} \mathrm{PO}_{3}\right)_{2}\right]$ & 330 & LMCT & 0 & $\begin{array}{l}\text { Octahedral/ } \\
\text { distorted Octahedral }\end{array}$ \\
\hline
\end{tabular}

PROPOSED STRUCTURES FOR THE METAL -GBM AND THE METAL-GPBM COMPLEXES

Analyses and comparisons of the electronic spectral data of the ligands, GBM, GPBM, and their metal complexes indicated the participation of the nitrogen atoms of the guanidinobenzimidazole ligand in the coordination of the ligand to the metalions.

The shifts in the position of the $v(\mathrm{P}=\mathrm{O})$ absorption band of the phosphonate moiety in the guanidinophosphonatebenzimidazole, (GPBM) ligand from $1265 \mathrm{~cm}^{-1}$ in the free ligand to $1141 \mathrm{~cm}^{-1}-1200 \mathrm{~cm}^{-1}$ in the metal complexes suggested the involvement of the $\mathrm{P}=\mathrm{O}$ in the coordination of the metal ions to the guanidinophosphonatebenzimidazole, (GPBM) ligand.
Thus, the following structures, Figures 31 and 32 can be proposed for the metal(II) complexes of guanidinobenzimidazole, (GBM) and guanidinophosphonatebenzimidazole, (GPBM), respectively from the Infra-red, UV-Visible spectroscopic data, and magnetic susceptibility measurements.

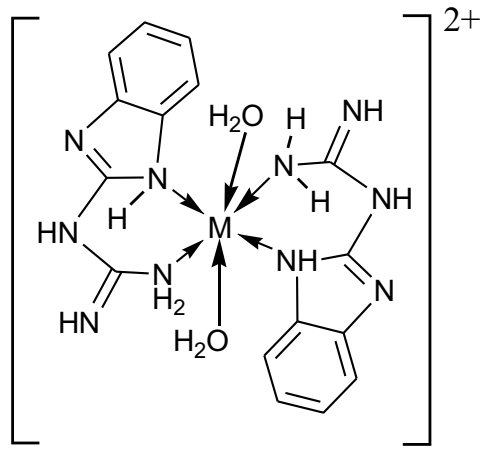

Figure 31: Proposed Structure for Metal(II) guanidinobenzimidazole complex. (Where $\mathrm{M}=\mathrm{Fe}, \mathrm{Co}$, $\mathrm{Ni}, \mathrm{Cu}$ and $\mathrm{Zn}$ ) 


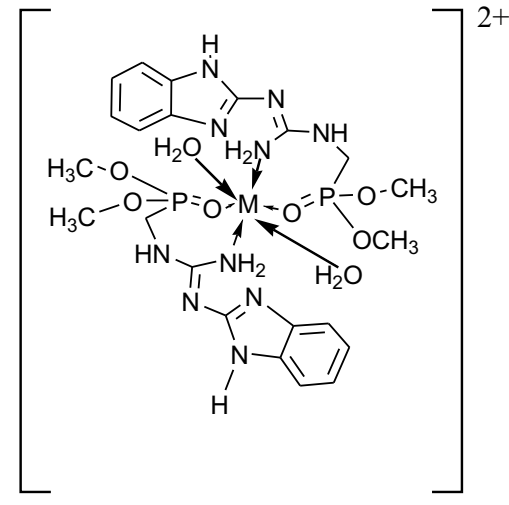

Figure 32: $\quad$ Proposed Structure for Metal(II)guanidinophosphonatebenzimidazole Where $\mathrm{M}=\mathrm{Fe}$, $\mathrm{Co}, \mathrm{Ni}, \mathrm{Cu}$ and $\mathrm{Zn}$

\section{CONCLUSION}

Guanidination of benzimidazole and phosphorylation of guanidinobenzimidazole were successfully carried out and the chelating properties investigated. The ligands and the metal complexes were characterized by elemental analysis, Infra-red, UV-Visible spectroscopic data, and magnetic susceptibility measurements.

The two ligands are bonded to the metal ions in different chelating modes. The metal ions coordinate to the guanidinobenzimidazole, (GBM) ligand through the imidazolic nitrogen and one of the guanidine nitrogen in position 12 to form six-membered rings.

The shifts in the position of the $v(\mathrm{P}=\mathrm{O})$ absorption band of the phosphonate moiety in the guanidinophosphonatebenzimidazole, (GPBM) ligand in the free ligand suggests the involvement of the $\mathrm{P}=\mathrm{O}$ bond in the coordination to the metal ions by the guanidinophosphonatebenzimidazole, (GPBM) ligand leading to the formation of five membered rings.

\section{REFERENCES}

Anderson, R. J., Bendell, D. J., and Groundwater, P. W. (2004).Ultraviolet-visible (UV-Vis) Spectroscopy. In: Organic Spectroscopic Analysis; Royal Society of Chemistry, Vol 22, pp 7-23

Andrade, N Ariza-Castolo, A. and Contreas, R;(1997); Versatile Behaviour of Guanidinobenzimidazole Nitrogen atoms toward protonation, Coordination and
Methylation; Heteroatom Chemistry, 8, pp.397-410.

Anitha, C., Sumathi, 1. S., Tharmaraj, 1.P. and Sheela, C. D. (2011). Synthesis, Characterization, and Biological Activity of Some Transition Metal Complexes Derived from Novel HydrazoneAzo Schiff Base Ligand; International Journal of Inorganic Chemistry, pp201, 1-8.

Bakir, S. R, Al-hamdani, A.A and Jarad. A. J.; (2013). Synthesis and Characterization of Mixed Ligands of Dithizone and Schiff Base Complexes with Selected Metal ions; Journalfor Pure Sciences, 9, pp 82-94.

Daniel, H. O. D. and Isabel, R. I. A. (2011); Concise Synthesis of Asymmetrical N,N'Disubstituted Guanidines.; Tetrahedron Letters, 5, pp 132.

FabiolaTéllez, HoracioLópez-Sandoval, Silvia E. Castillo-Blum, and

NoráhBarba-Behrens; (2008); Coordination Behavior of Benzimidazole, 2-Substituted Benzimidazoles and Benzothiazoles, Towards Transition Metal ions; ARKIVOC (V) pp. 245-275.

Ferrero, J.R, (1971); Low frequency Vibrations of Inorganic and coordination Compounds, Wiley-Interscience, New York.

Katritzky, A. R. and Rogovoy, B. V. (2005).Recent Developments in Guanylating Agents. ARKIVOC(IV), pp.49 - 87.

Khatiwora, E., Mundhe, K., Deshpande, N.R. and Kashalkar. R.V;. (2012). Anthelmintic activity of transition metal complexes of somebenzamides;. Der PharmaChemica, 4, pp 1264-1269.

Kong, E, Ritter, G and Kulsheshtha, S.K; (1985); The Nature of Spin State Transitions in Solid Complexes of Iron (II) and the Interpretation of Some Associated Phenomena, Chemical Reviews, 85, (3), pp 219-234.

Krishnamurthy Ramadas and NatarajanSrinivasan (1995).;An expedient synthesis of substituted guanidines.; Tetrahedron Letters, Elsevier Science. 36, pp 2841-2844.

Lopez, N. A., Castolo, A. A, Contreras, R. (1997) Versatile Behavior of 2-Guani dinobenzimidazole Nitrogen Atoms toward Protonation Coordination and Methylation Heteroatom Chemistry, 8, pp 
397-410.

Magsoodloua, M.T, Nourollah, Hazeria, S.M.Habibi-Khorassania, L.S, Mohammad,K.R; and Mojtaba, R.(2006); Diastereoselective synthesis of phosphonate esters by reaction between triphenylphosphite and acetylenic esters in the presence of $\mathrm{NH}$-acid compoumds, ARKIVOC, 13, pp.117-123.

Malek, Sedlavora, E; Andriamanity, F; Sollei, C, (2006); Activity of Transition Metal Complexes of some Benzamides; Journal of Pharmacentical Sciences, 75, pp 3-9.

Malek, T. M.;Sayyed, M. H.;Reza, H.; Nourallah, H.;Seyed, S. S. and Mohsen, R. (2011).; An efficient and simple synthesis of $\alpha$ amino phosphonates as drug like molecules catalyzed by silica supported per chloric acid $\left(\mathrm{HClO}_{4}-\mathrm{SiO}_{2}\right) ;$ Arabian Journal of Chemistry. 4, pp 481-485.

Osowole, A.A (2012). Synthesis, Spectroscopic Characterization, In-vitro Antibacterial and Antiproliferative Activities of Some Metal(II) Complexes of 3,4 dihydronaphthalen-1 $(2 \mathrm{H})$ one Schiff Base. EXCLI Journal, (11), pp 338-345

Padmaja, M., Pragathi, J. and Kumari, C.G (20 011 ). Synthesis, Spectral Characterization, Molecular Modeling and Biological Activity of First Row Transition Metal Complexes with Schiff Base Ligand Derived from Chromone-3Carbaldehyde and o-Amino Benzoic Acid.Journal of Chemical and Pharmaceutical
Research, 3, pp 602-613

Rao, C.N.R, Exkataraghavax, R; and Kasturi, T.R, (1964); Contribution to the Infrared Spectra of Organosulphur Compounds; Canadian Journal of Chemistry, 42, pp 36-42

Reddy, M. V. N., Kumar, B. S.,Balakrishna, A.. Reddy, C. S., Nayak, S. K.and Reddy, C. D. (2007). One-pot Synthesis of Novel $\alpha$ AminoPhosphonates using Tetramethyl guanidine as a Catalyst, $A R K I V O C, 15, \mathrm{pp}$ 246-254

Singh, G, Singh, P A, Singh, K. (2002); Synthesis and structural studies of some bivalent metal complexes with bidentate Schiff base ligands; Proceedings of the National Academic Sciences, India, 72, pp 87-94.

Sonmez, M. (2001). Synthesis and Characterization of Copper(II), Nickel(II), Cadmium(II), Cobalt(II) and Zinc(II) Complexes with 2-Benzoyl-3Hydroxy-1-Naphthylamino-3-Phenyl-2 Propen-1-on.Turkish Journal of Chemistry, 25, pp 181-185.

Strivastava, S. D. and Sen, J. P; (2008). Synthesis and Biological Evaluation of 2Aminobenzothiazole Derivatives, Indian Journal of Chemistry, 47 (B), pp 1583-1586.

Yadav, P. S. and Devprakash, S. G. P; (2011); Benzothiazole: Different Methods of Synthesis and Diverse Biological Activities, International Journal of Pharmaceutical Sciences and Drug Research, 3, pp 1-71 
APPENDICES

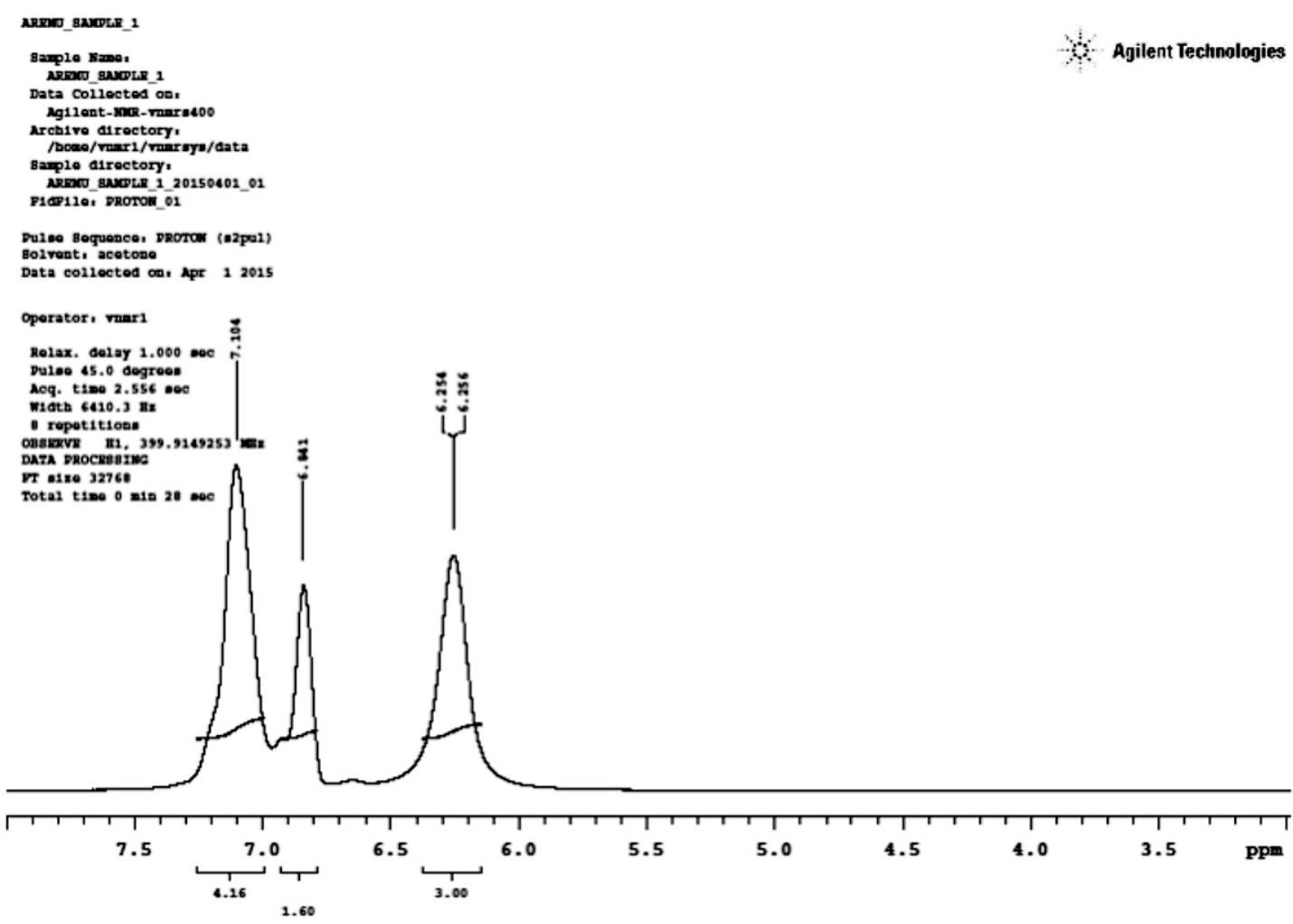

Figure 1: ${ }^{1} \mathrm{H}-\mathrm{NMR}$ Spectrum of Guanidinobenzimidazole

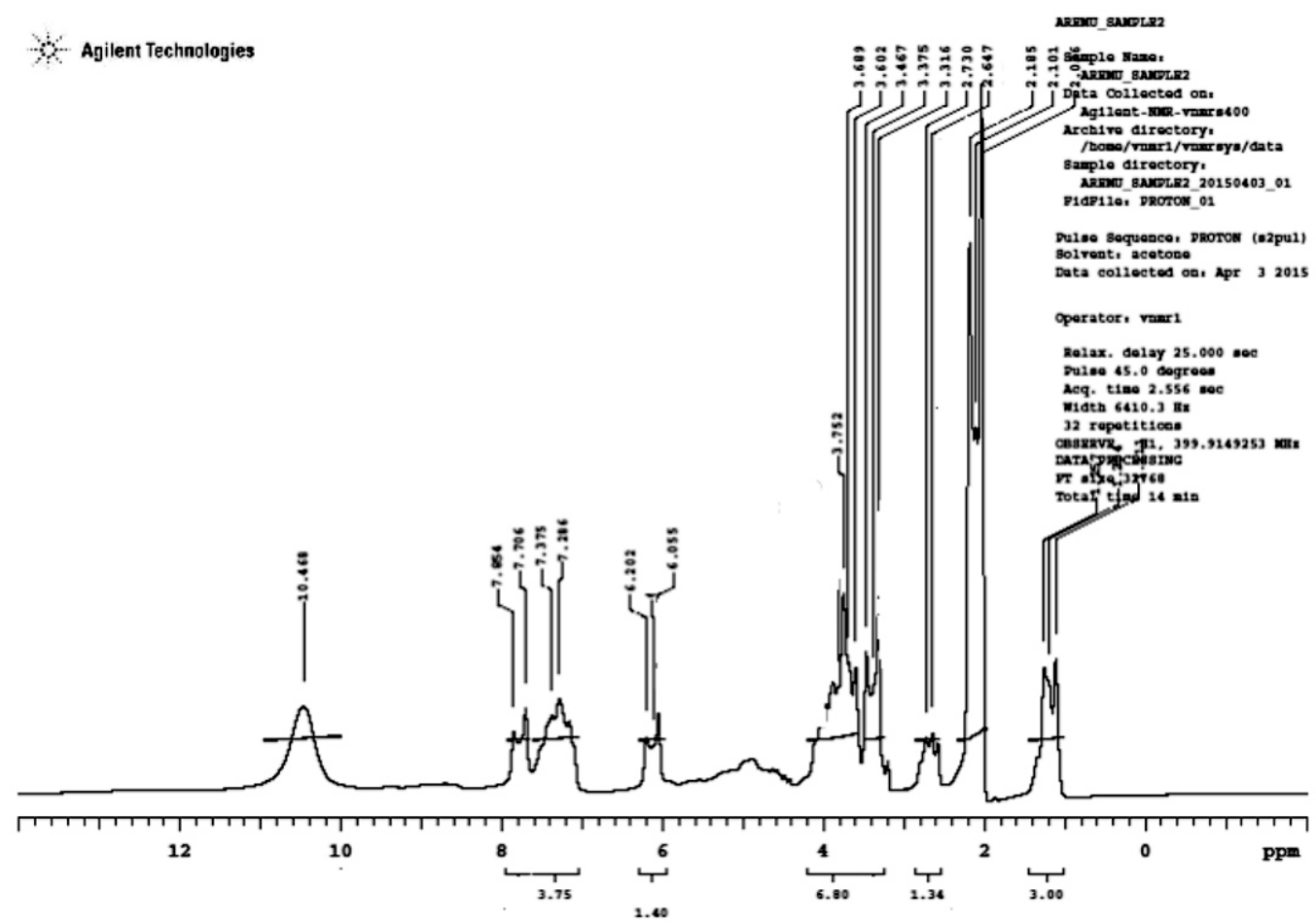

Figure $2:{ }^{1} \mathrm{H}-\mathrm{NMR}$ Spectrum of guanidinophosphonatebenzimidazole 


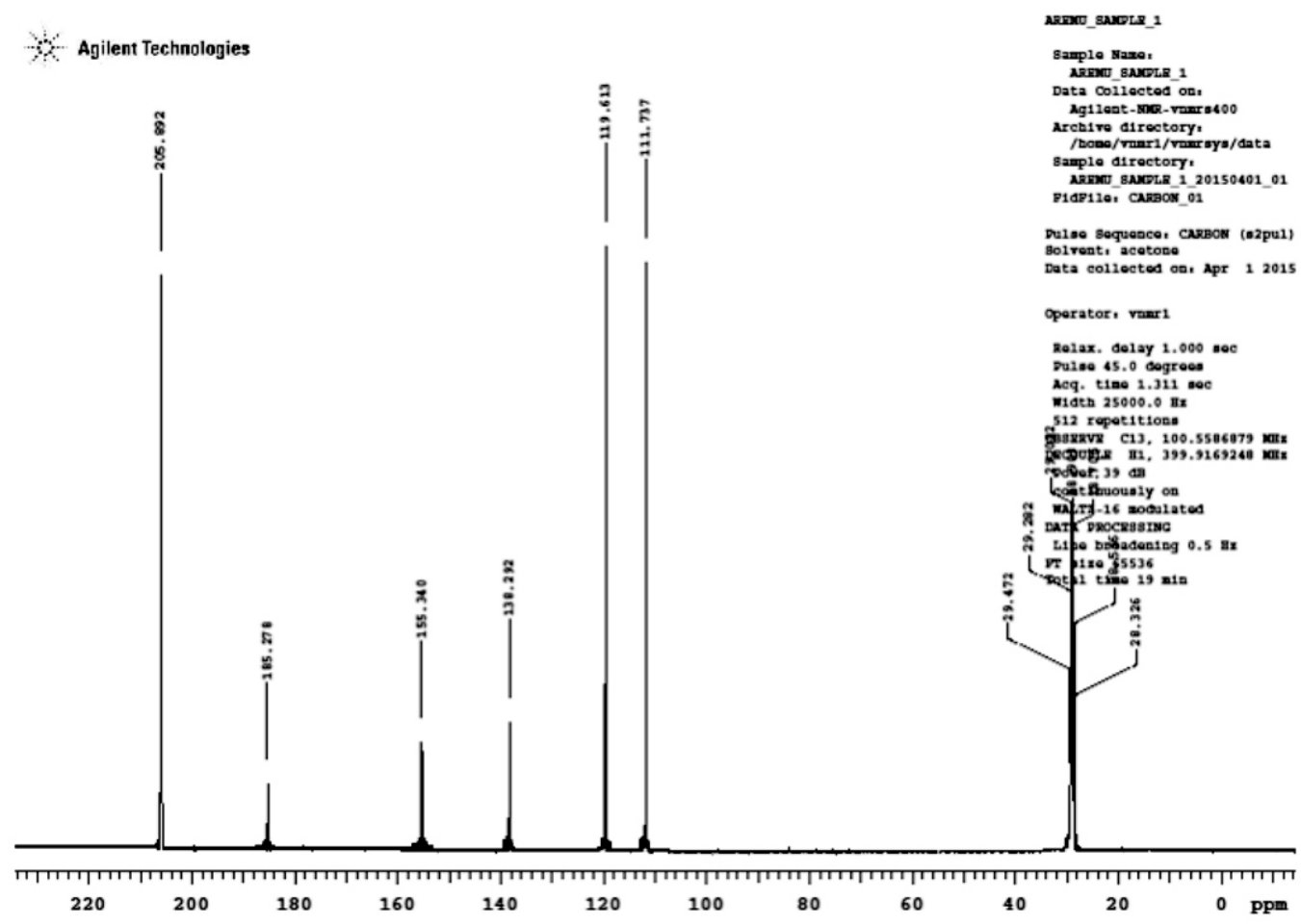

Figure $3:{ }^{13} \mathrm{C}-\mathrm{NMR}$ Spectrum of Guanidinobenzimidazole

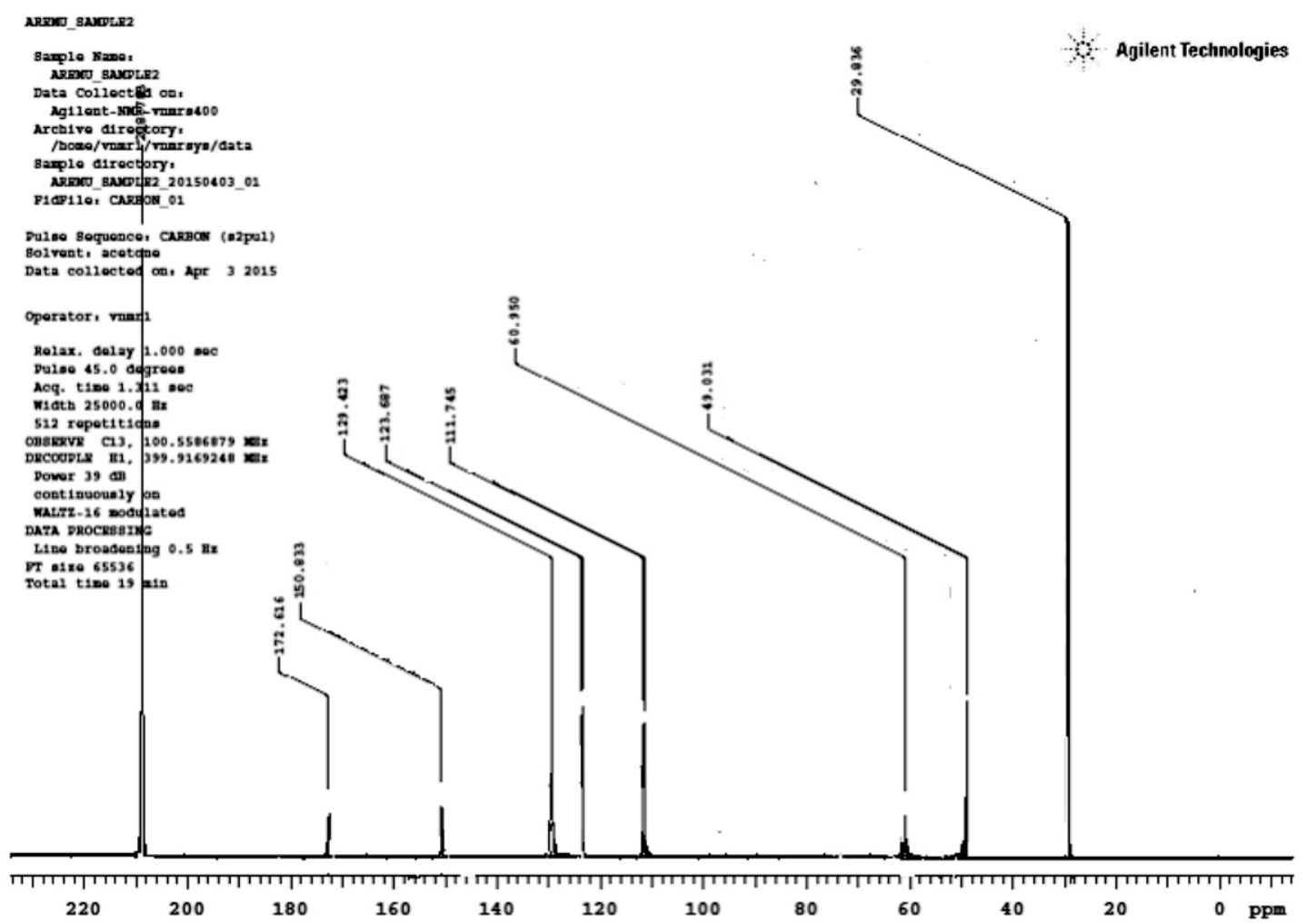

Figure $4:{ }^{13} \mathrm{C}$-NMR Spectrum of Guanidinophosphonatebenzimidazole 


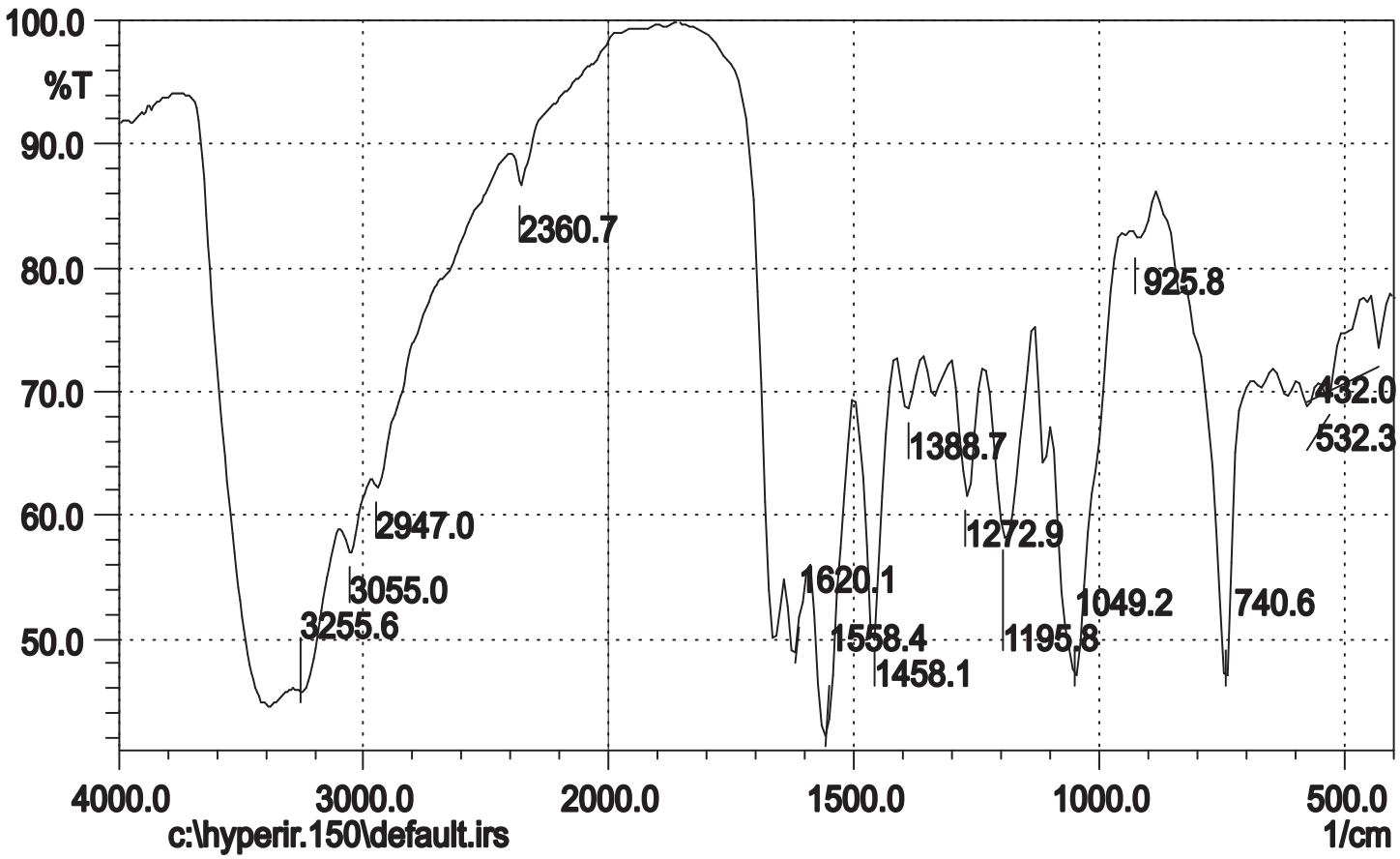

Figure 7: FT IR spectrum of guanidinobenzimidazole

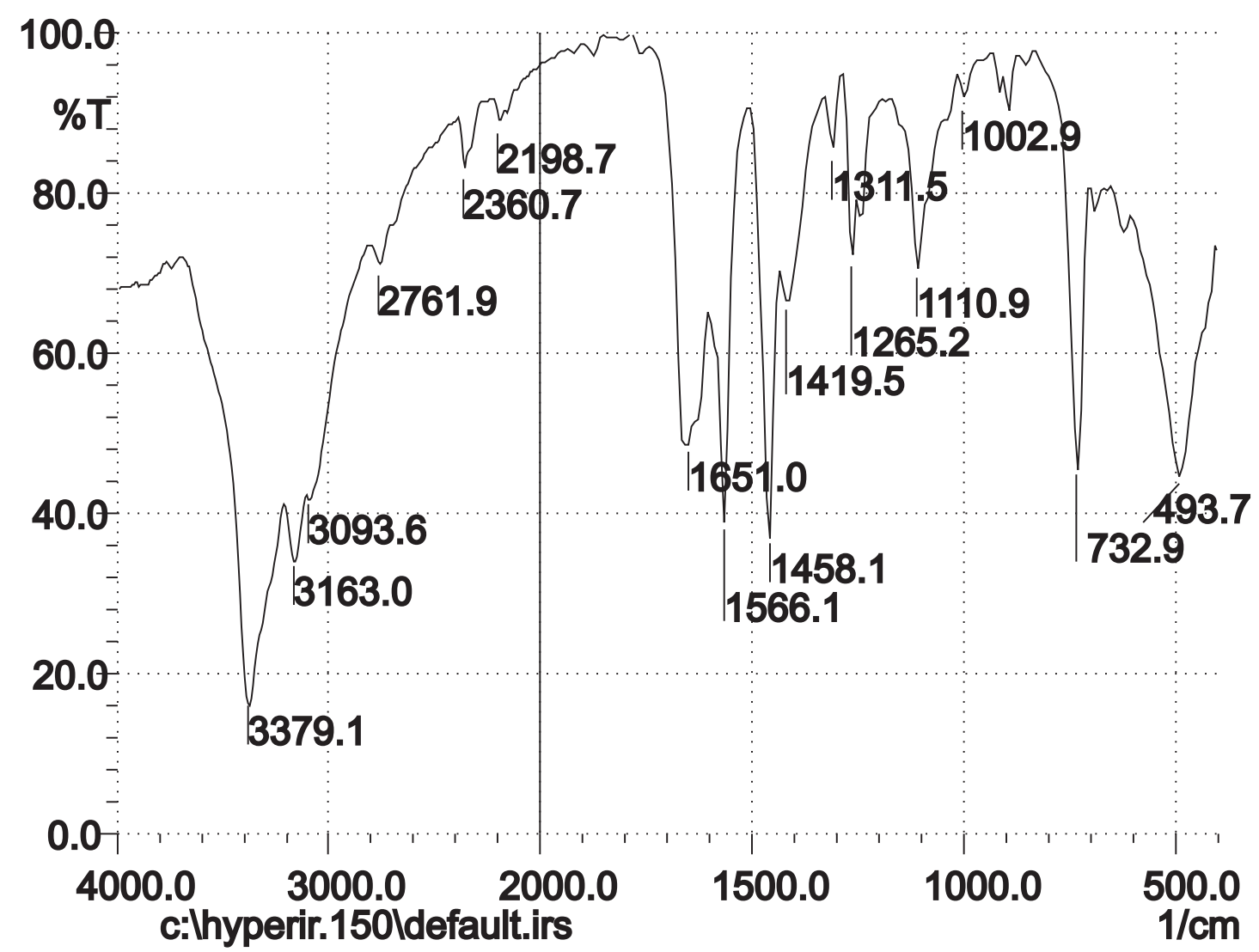

Figure 8: FT IR spectrum of guanidinophosphonatebenzimidazole 


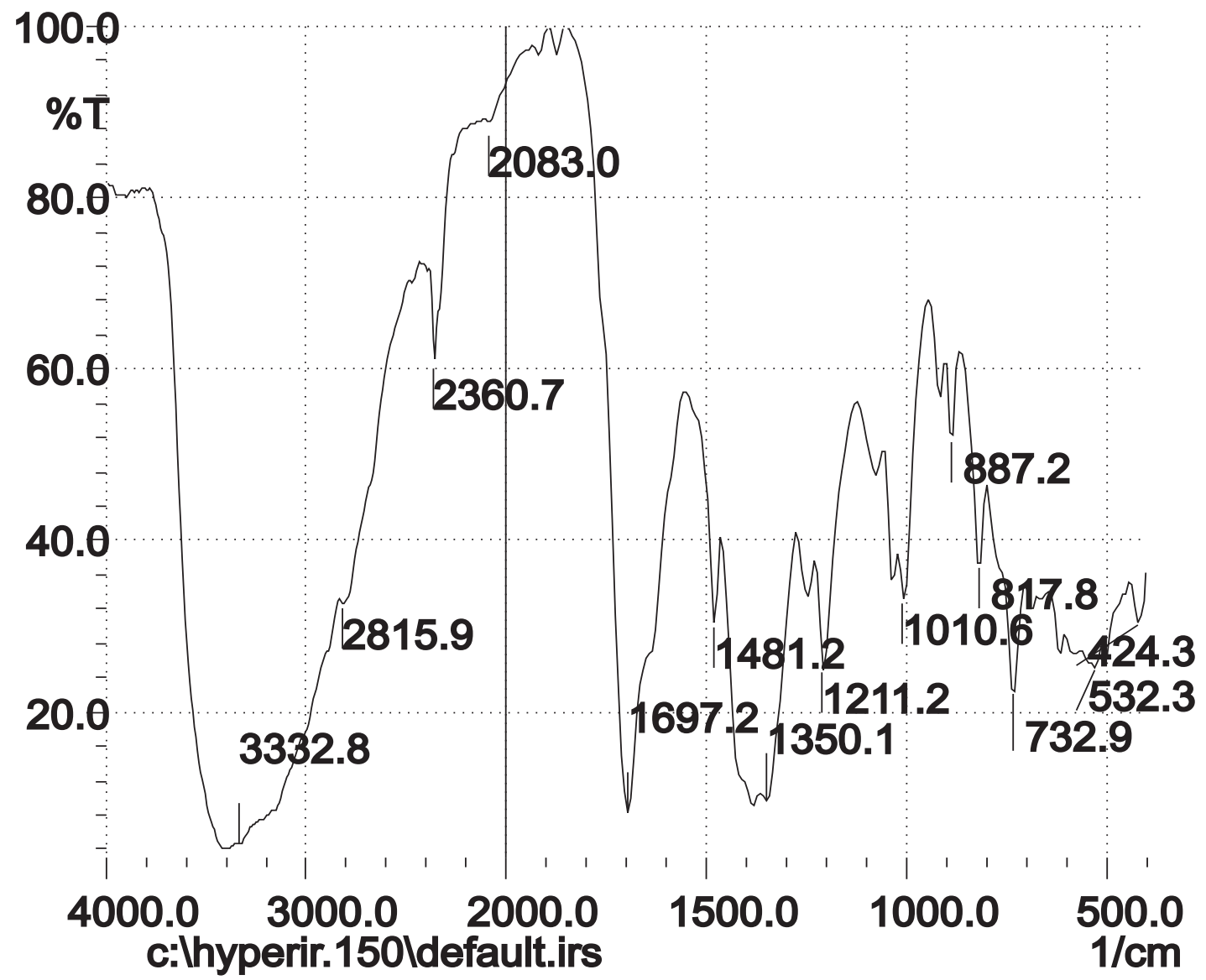

Figure 9: FT IR spectrum of Fe - guanidinobenzimidazole complex

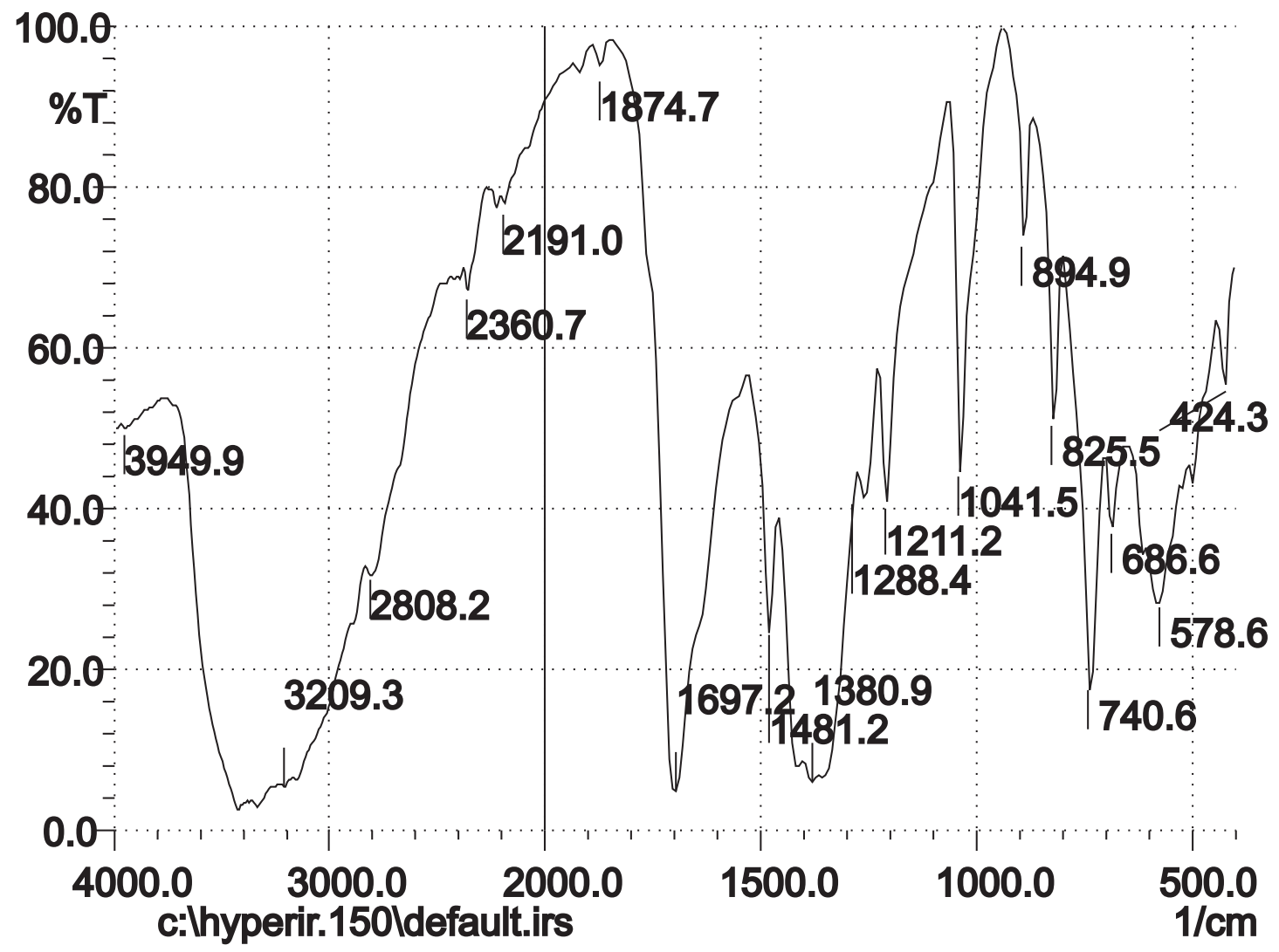

Figure 10 FT IR spectrum of Co - guanidinobenzimidazole complex 


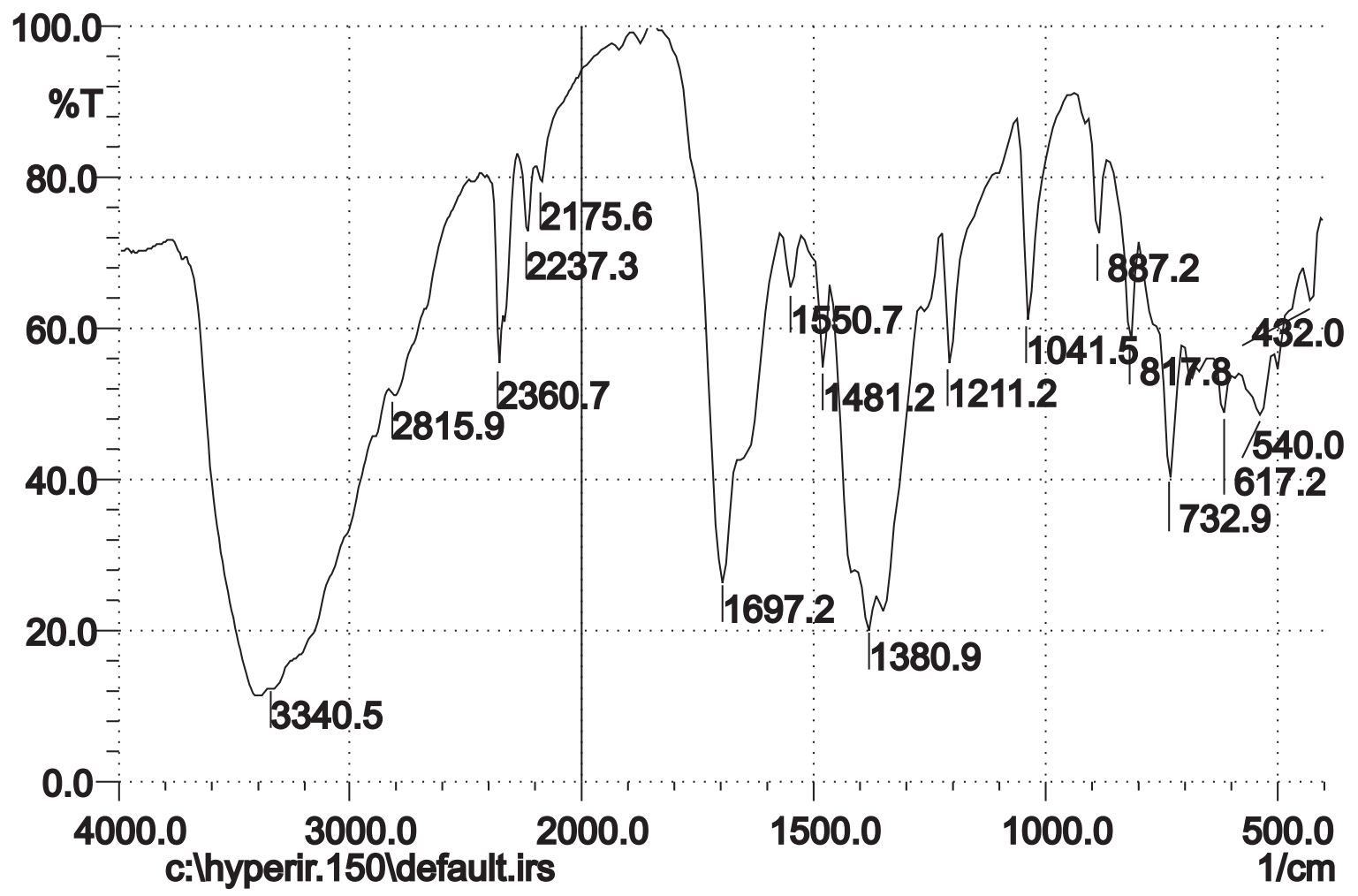

Figure 11: FT IR Spectrum of Ni - guanidinobenzimidazole complex

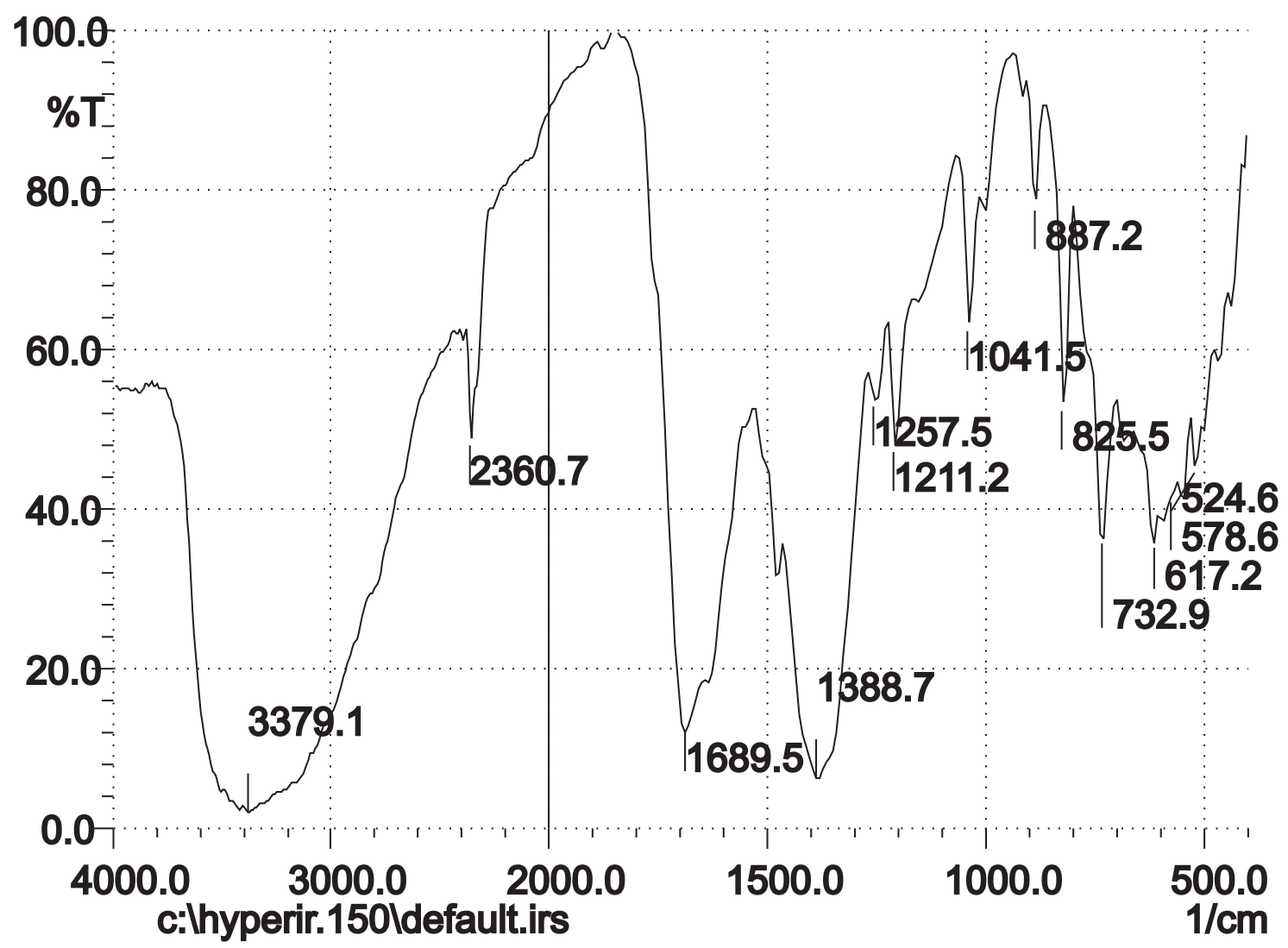

Figure 12: FT IR spectrum of $\mathrm{Cu}$ - guanidinobenzimidazole complex 


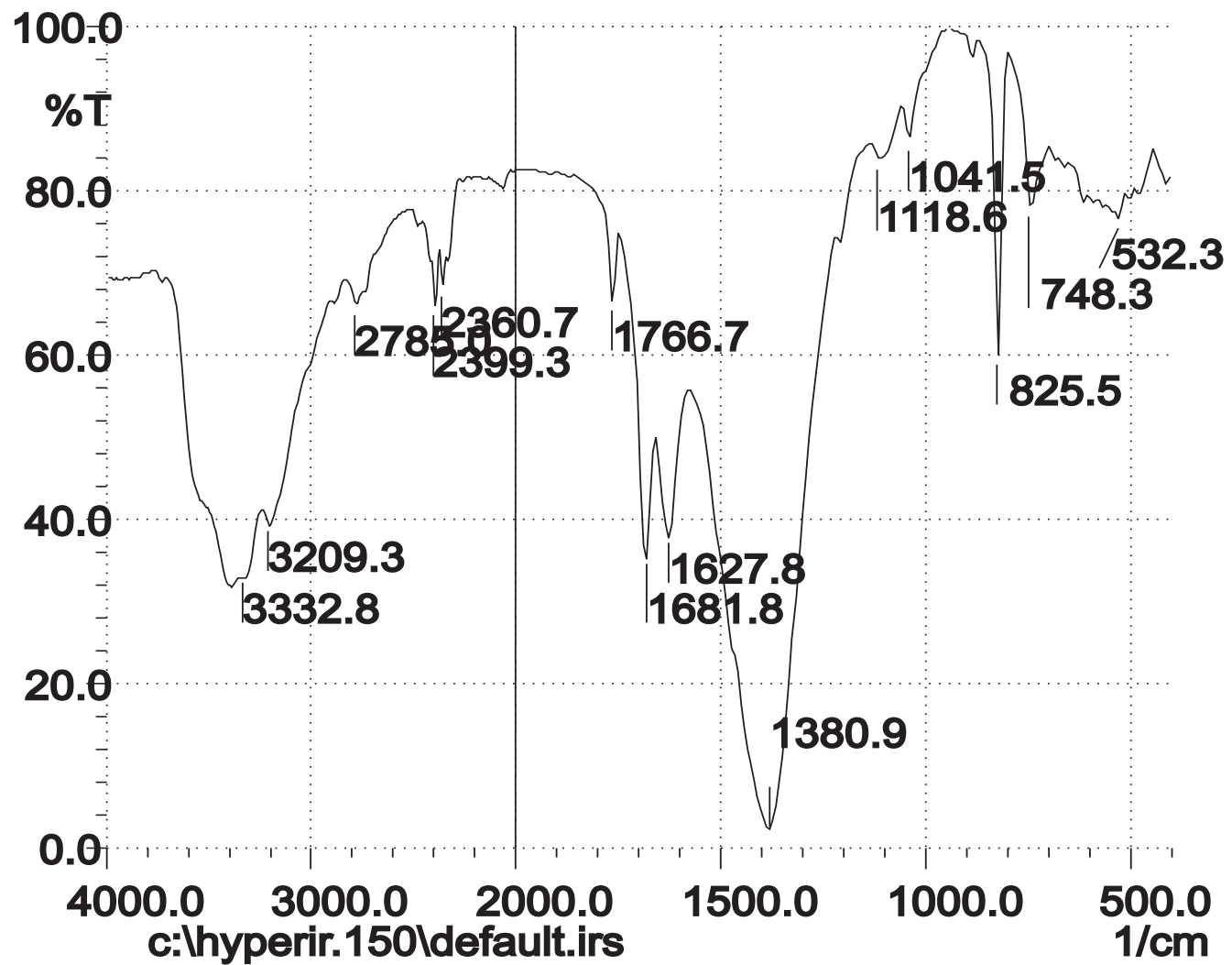

Figure 13: FT IR spectrum of $\mathrm{Zn}$ - guanidinobenzimidazole complex

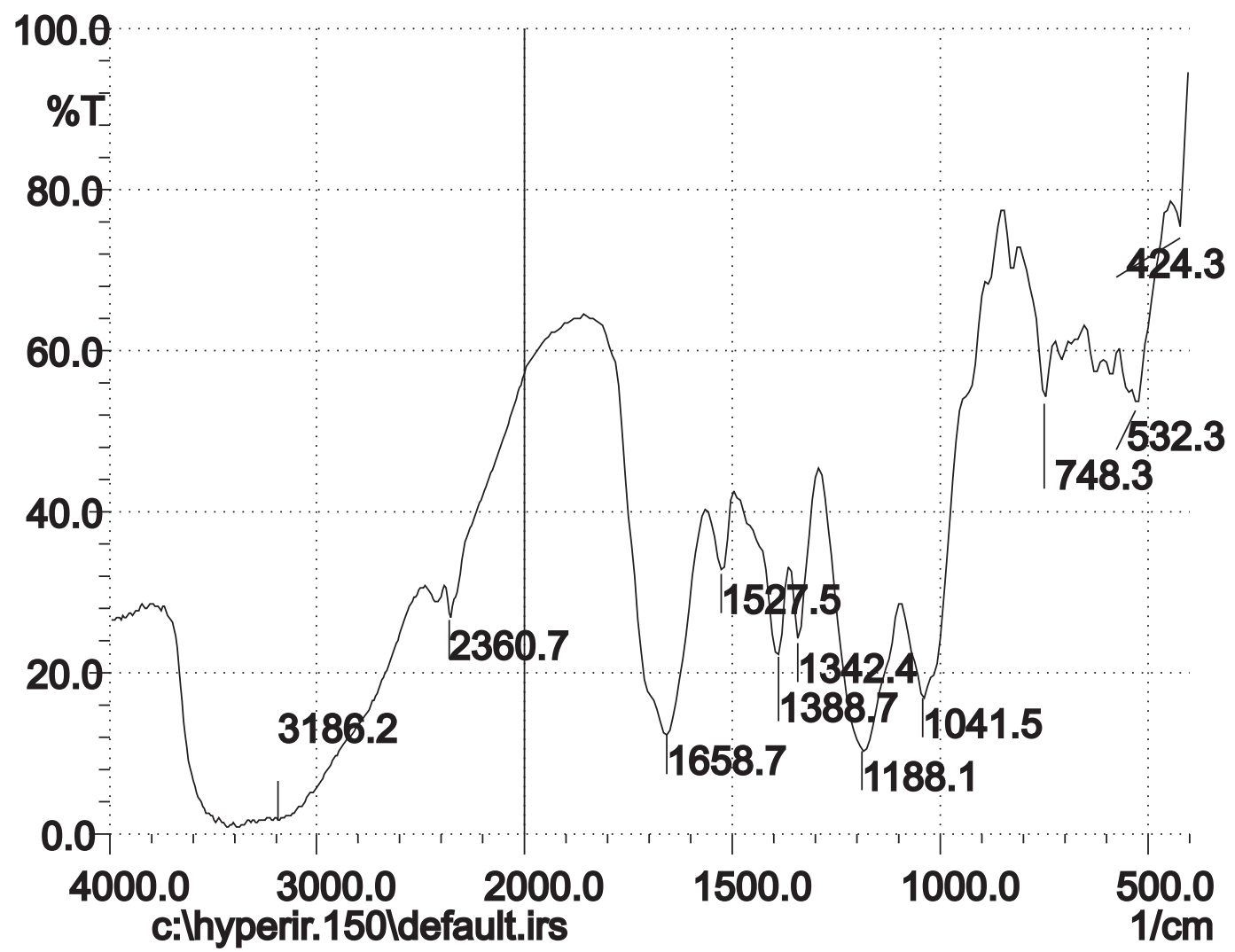

Figure 14: FT IR spectrum of Fe - guanidinophosphonatebenzimidazole complex 


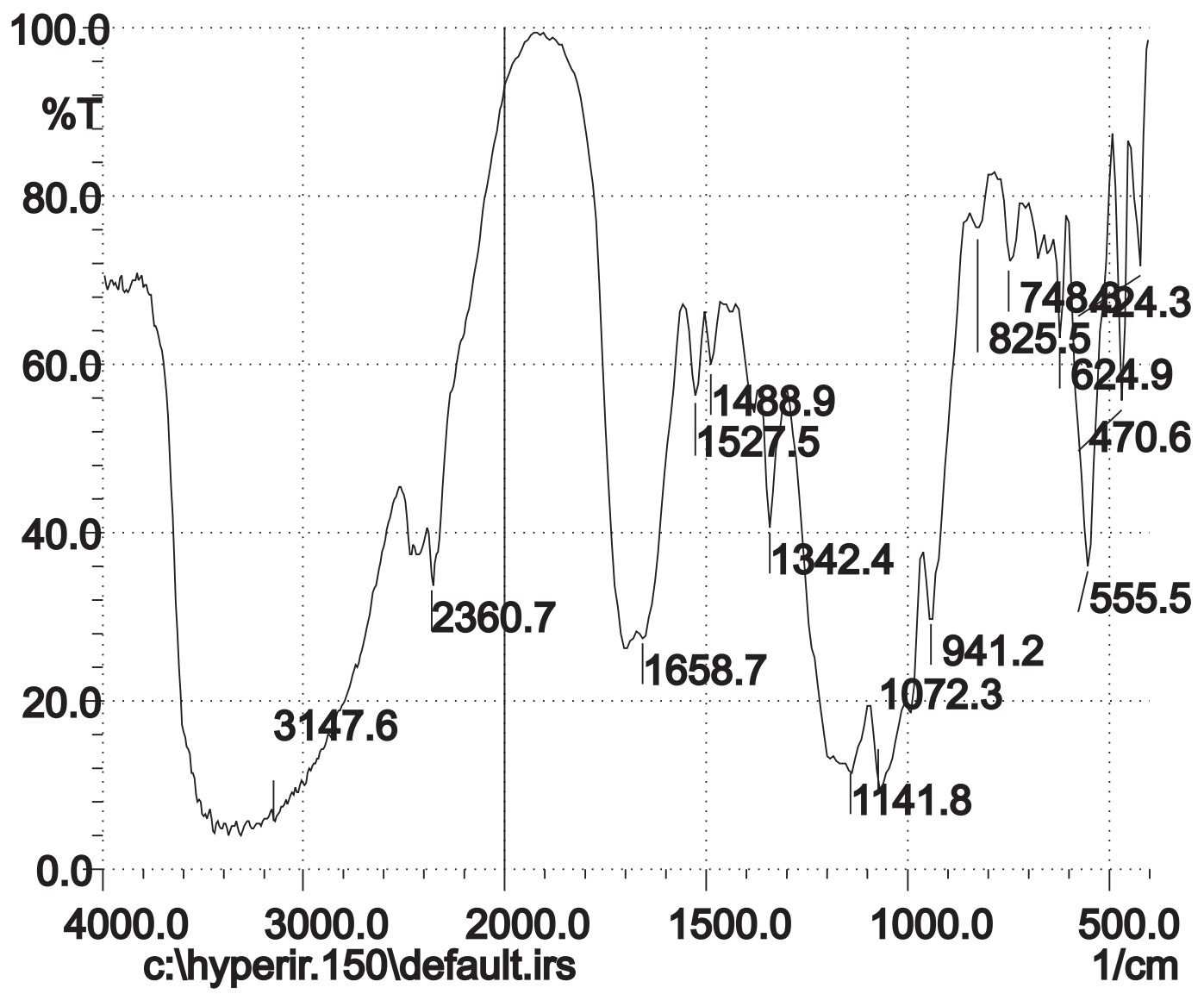

Figure 15: FT IR spectrum of Co - guanidinophosphonatebenzimidazole complex

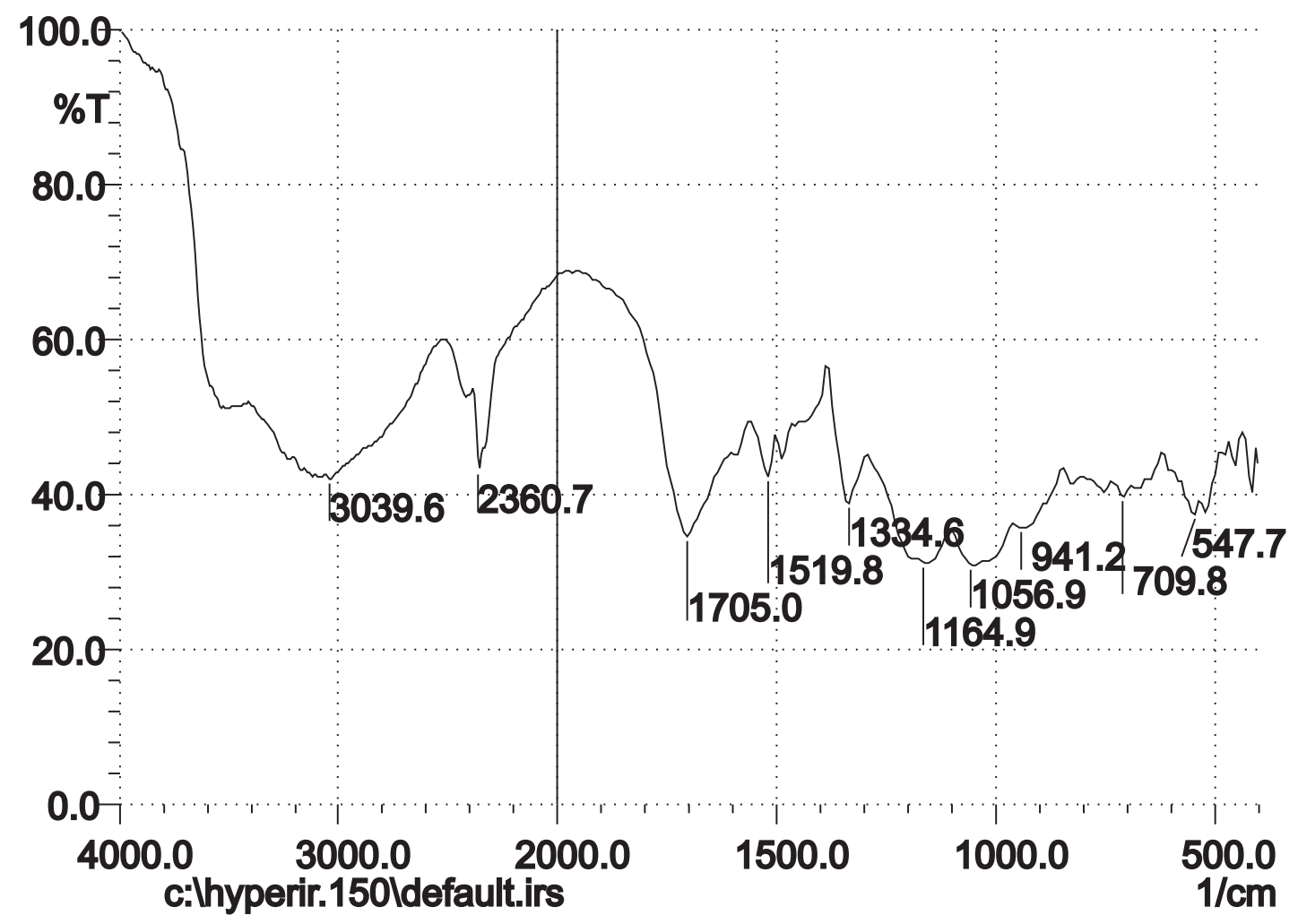

Figure 16: FT IR spectrum of Ni - guanidinophosphonatebenzimidazole complex 


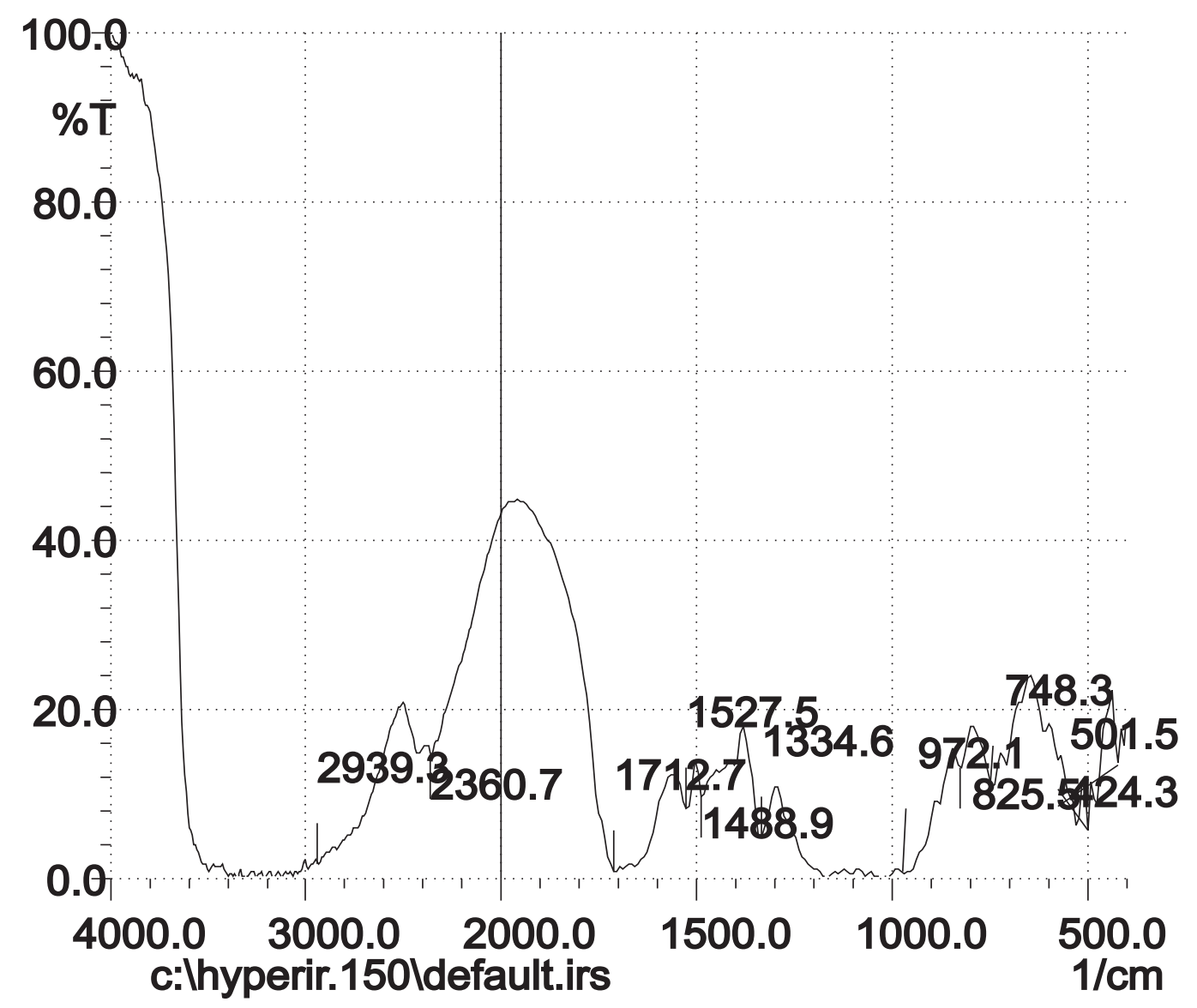

Figure 17: FT IR spectrum of $\mathrm{Cu}$ - guanidinophosphonatebenzimidazole complex

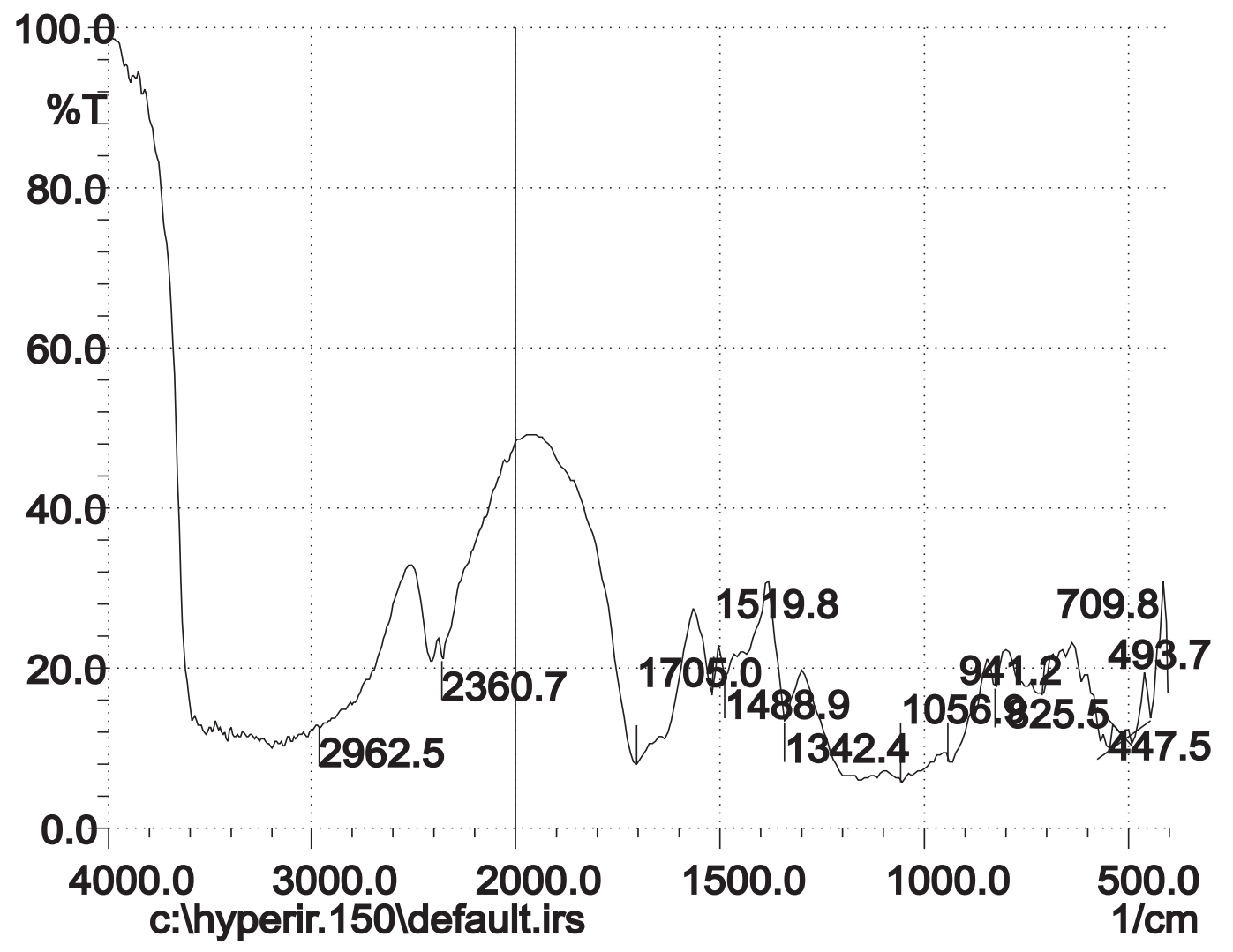

Figure 18: FT IR spectrum of $\mathrm{Zn}$ - guanidinophosphonatebenzimidazole complex 


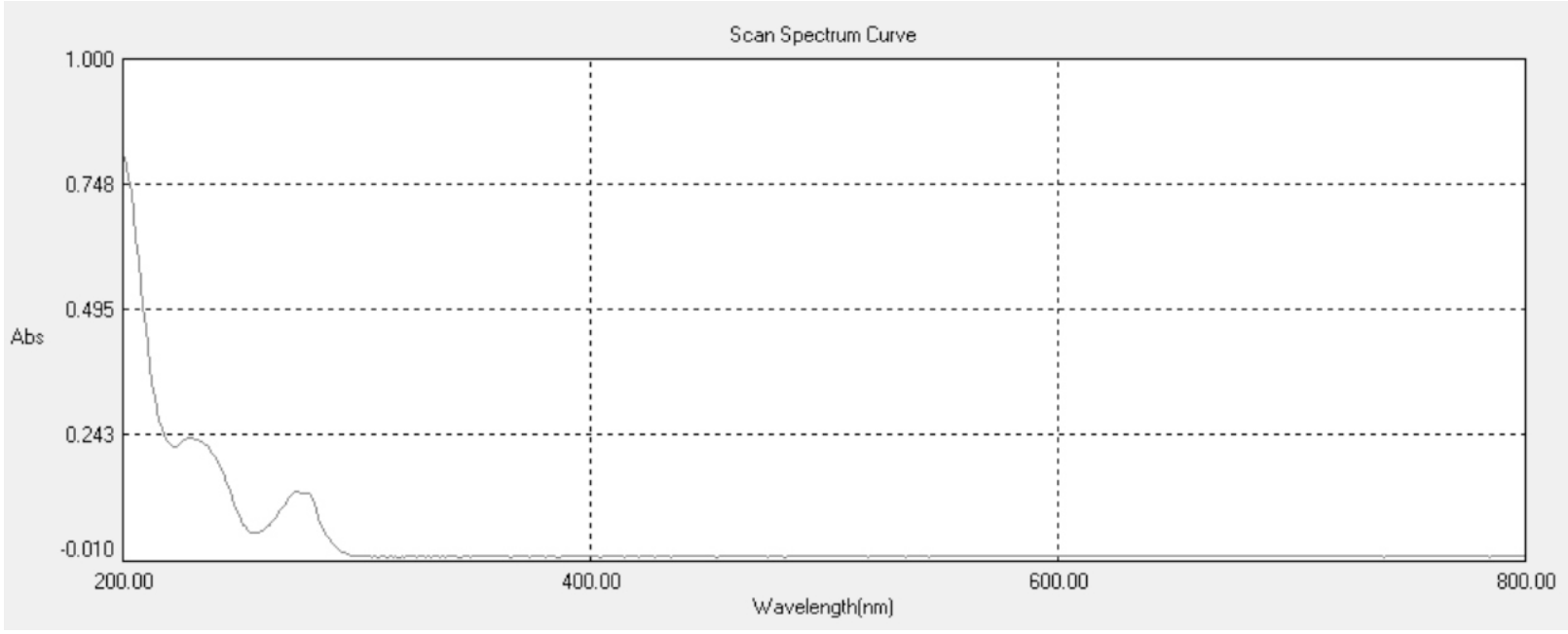

Figure 19: UV-Visible spectrum of guanidinobenzimidazole

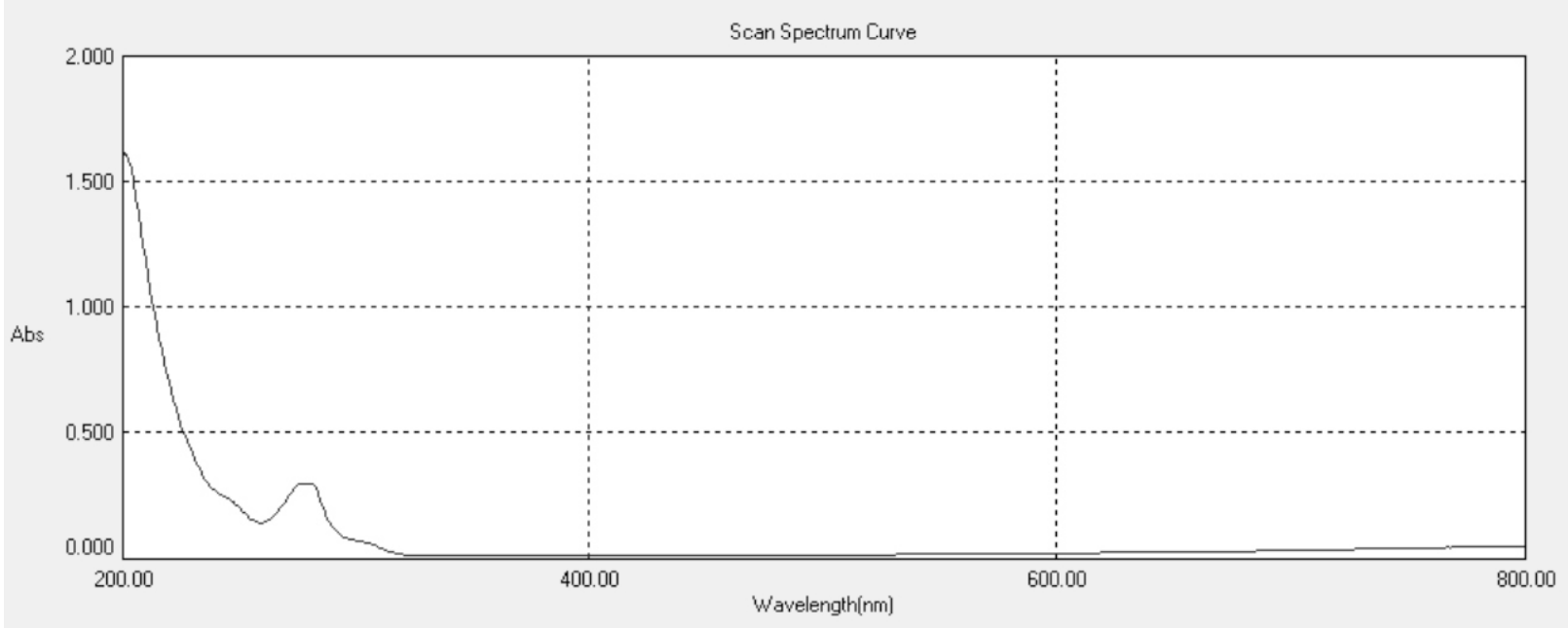

Figure 20: UV-Visible spectrum of guanidinophosphonatebenzimidazole

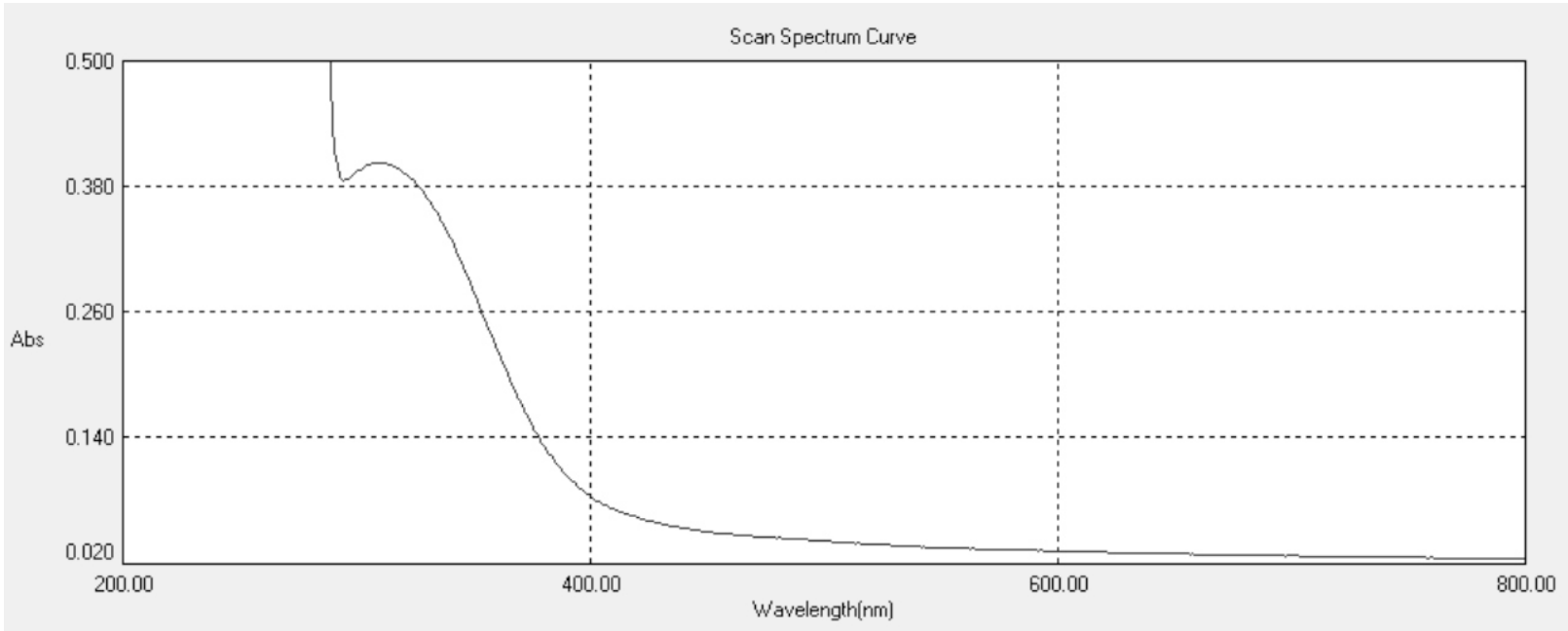

Figure 21: UV-Visible spectrum of Fe - guanidinobenzimidazole complex 


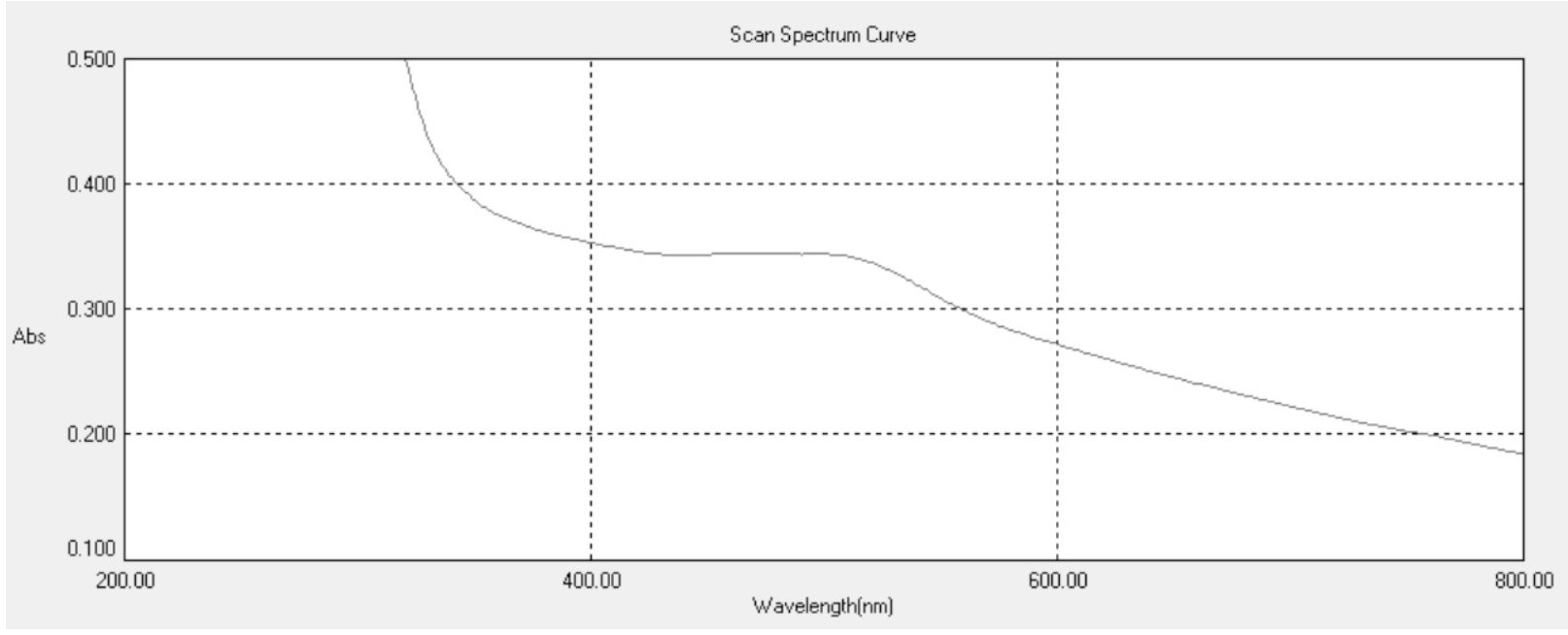

Figure 22: UV-Visible spectrum of Co - guanidinobenzimidazole complex

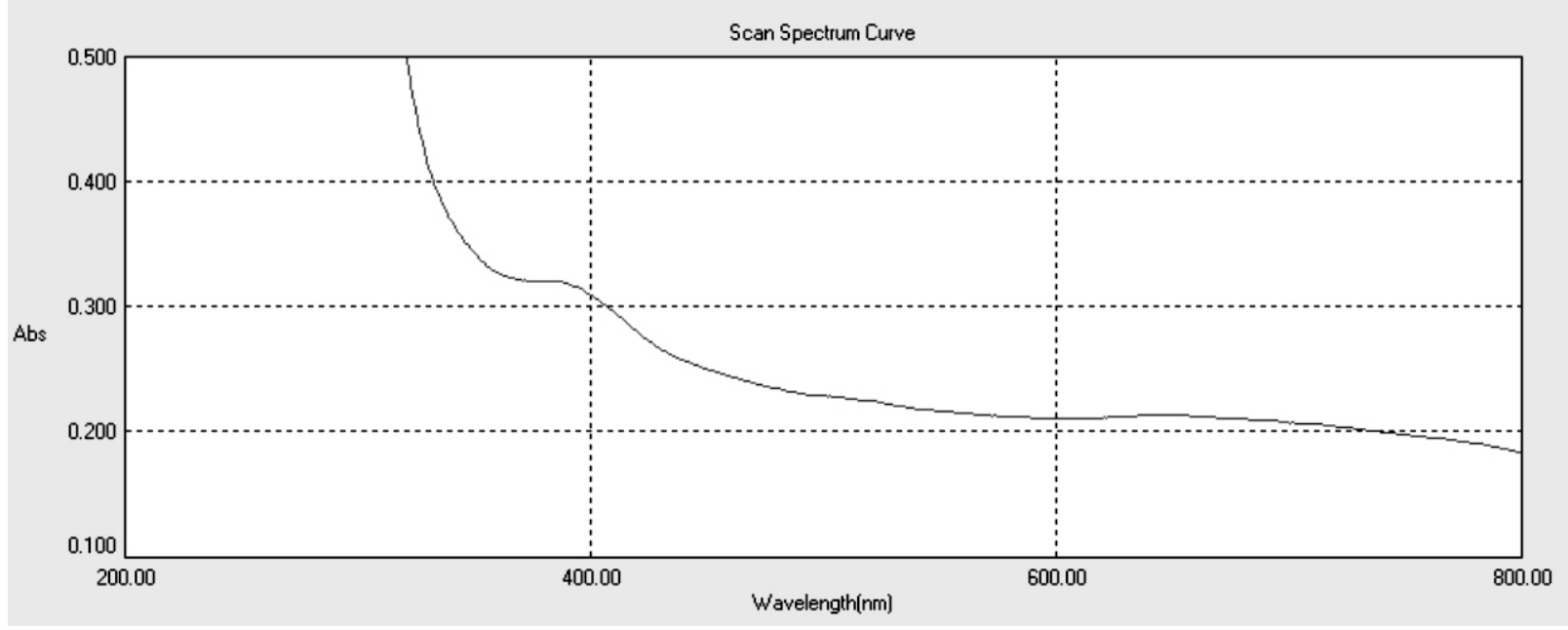

Figure 23: UV-Visible spectrum of Ni - guanidinobenzimidazole complex

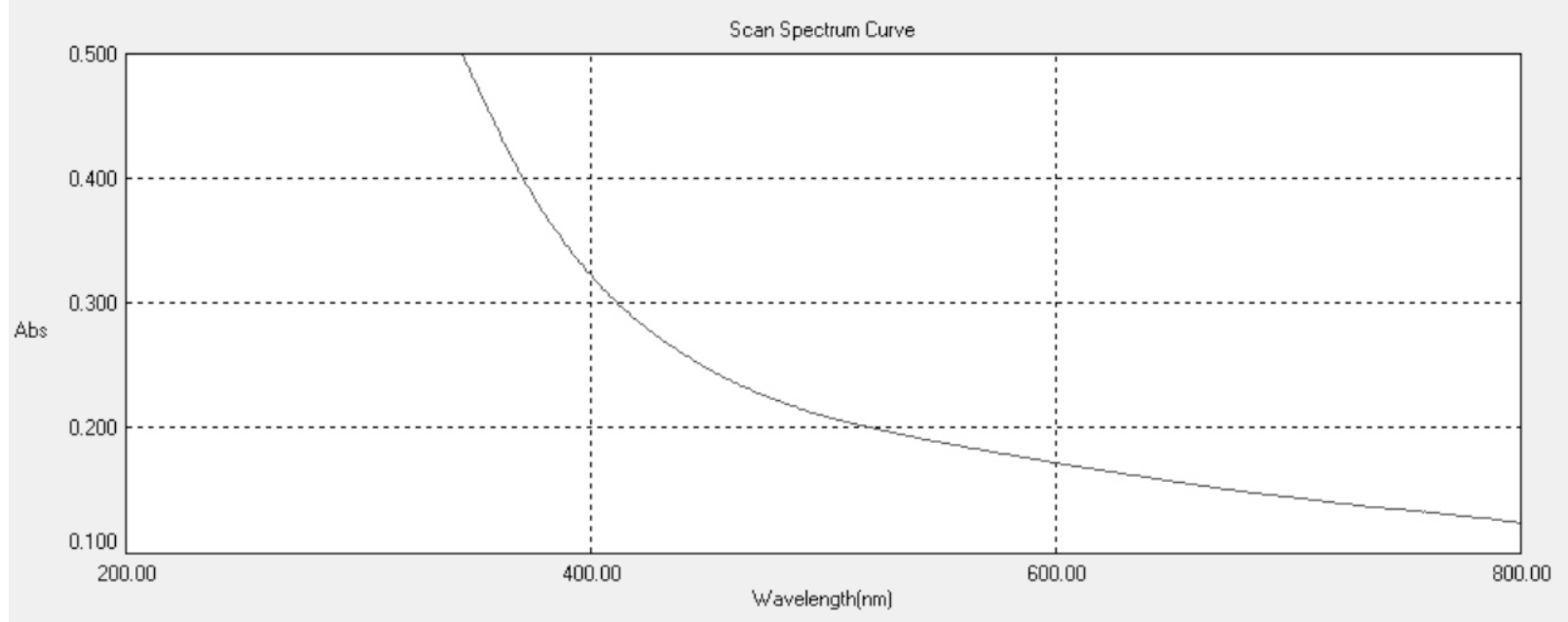

Figure 24: UV-Visible spectrum of $\mathrm{Cu}$ - guanidinobenzimidazole complex 


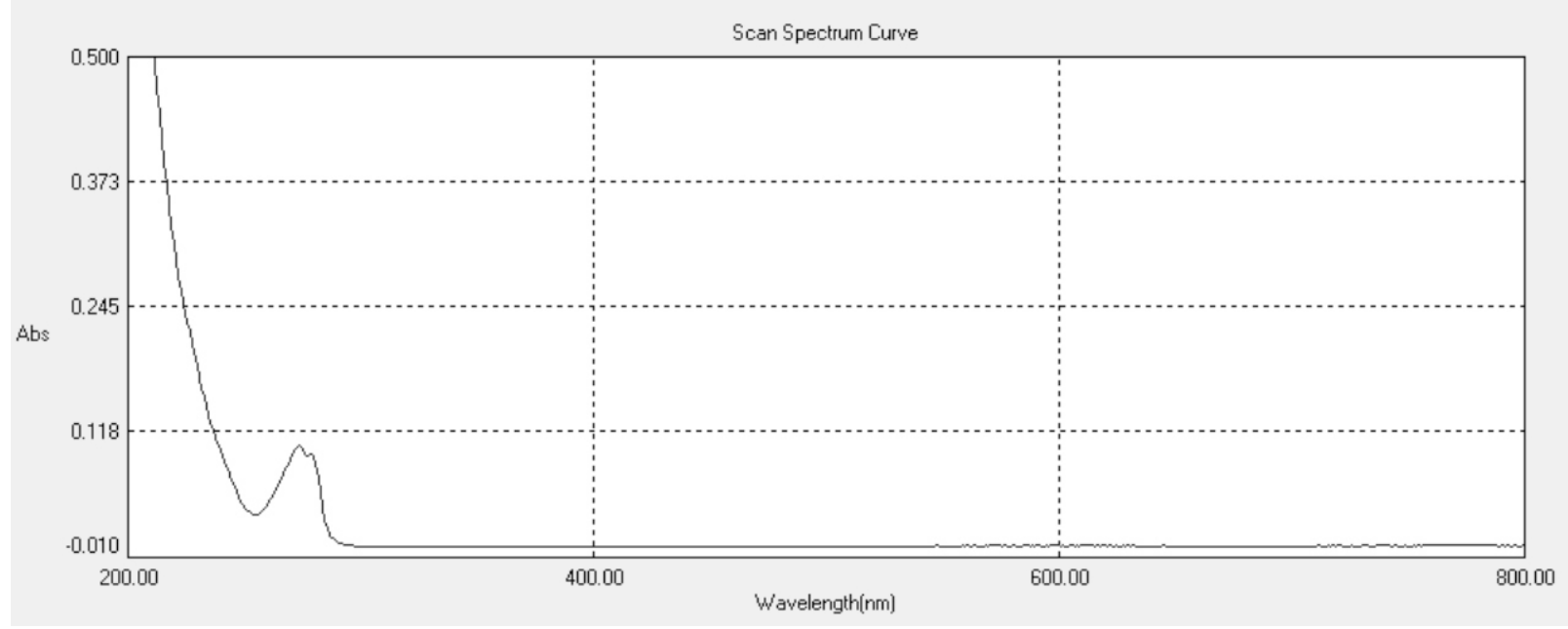

Figure 25: UV-Visible spectrum of $\mathrm{Zn}$ - guanidinobenzimidazole complex

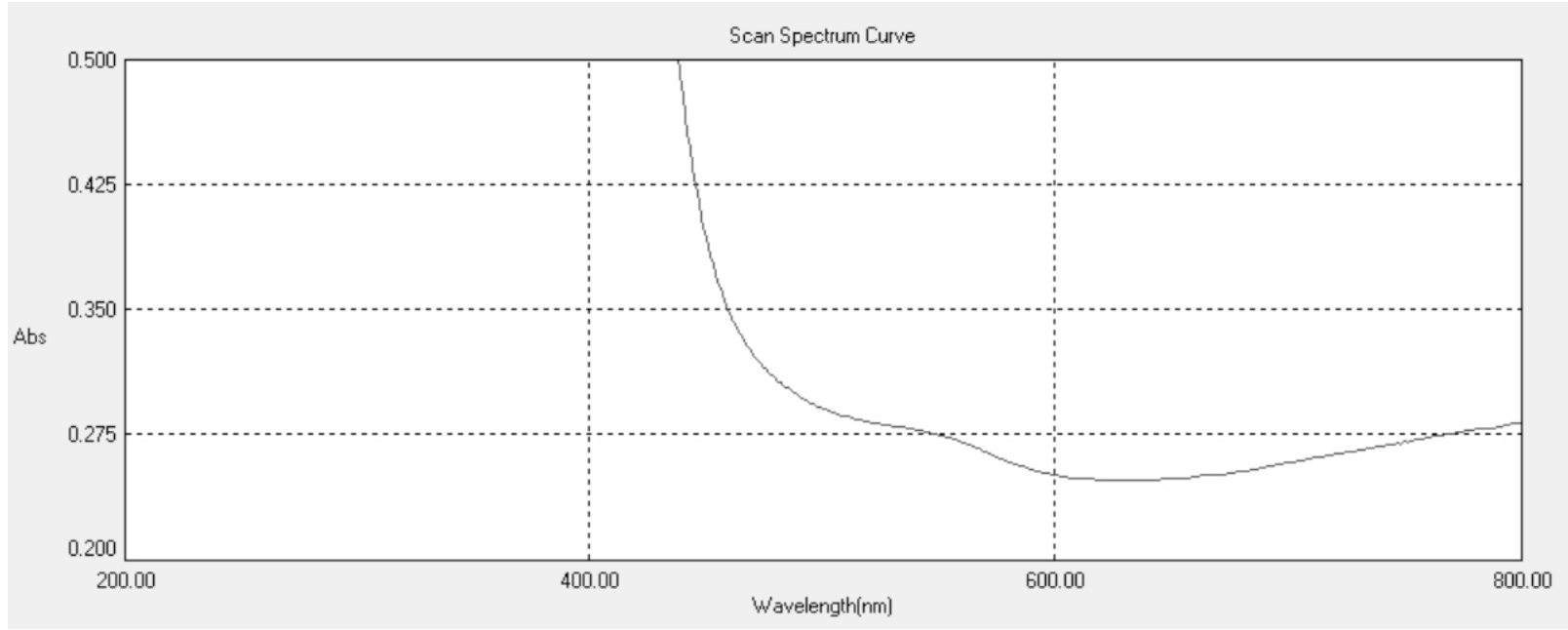

Figure 26: UV-Visible spectrum of Fe - guanidinophosphonatebenzimidazole complex

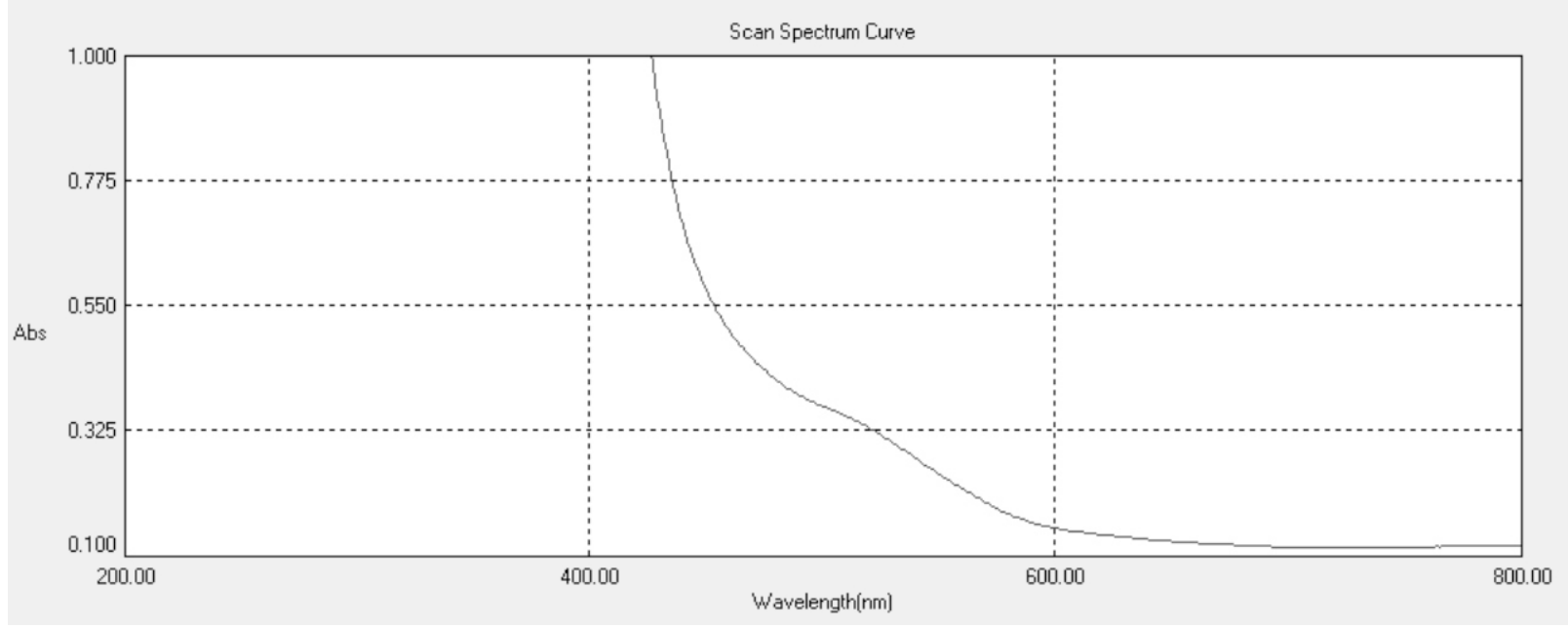

Figure 27: UV-Visible spectrum of Co - guanidinophosphonatebenzimidazole complex 


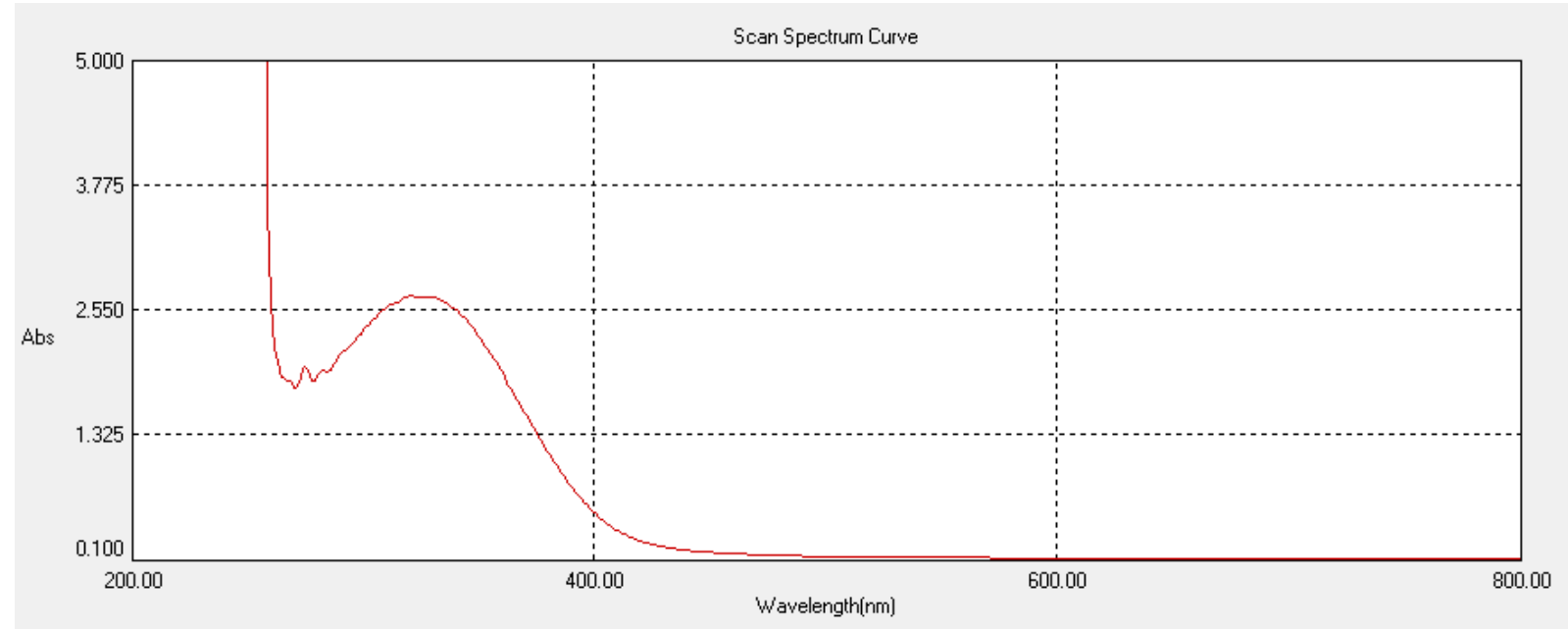

Figure 28: UV-Visible spectrum of $\mathrm{Ni}$ - guanidinophosphonatebenzimidazole complex

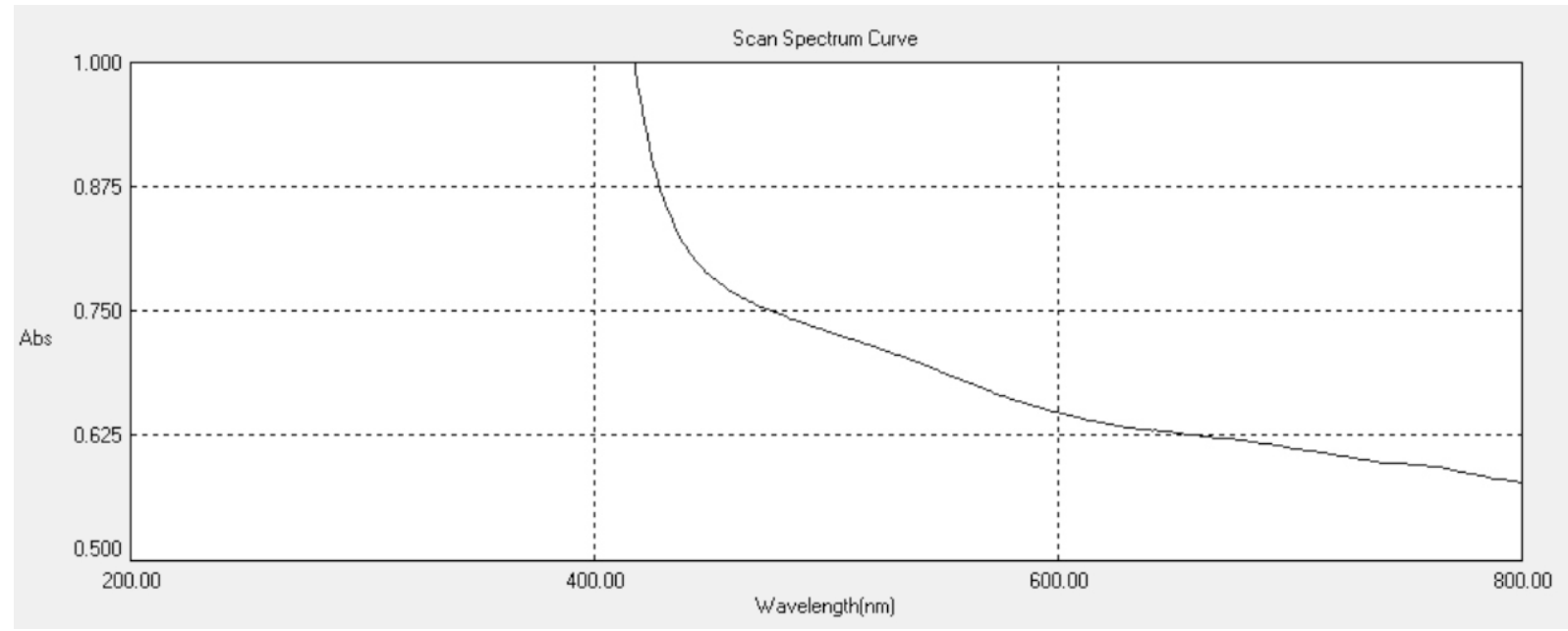

Figure 29: UV-Visible spectrum of $\mathrm{Cu}$ - guanidinophosphonatebenzimidazole complex

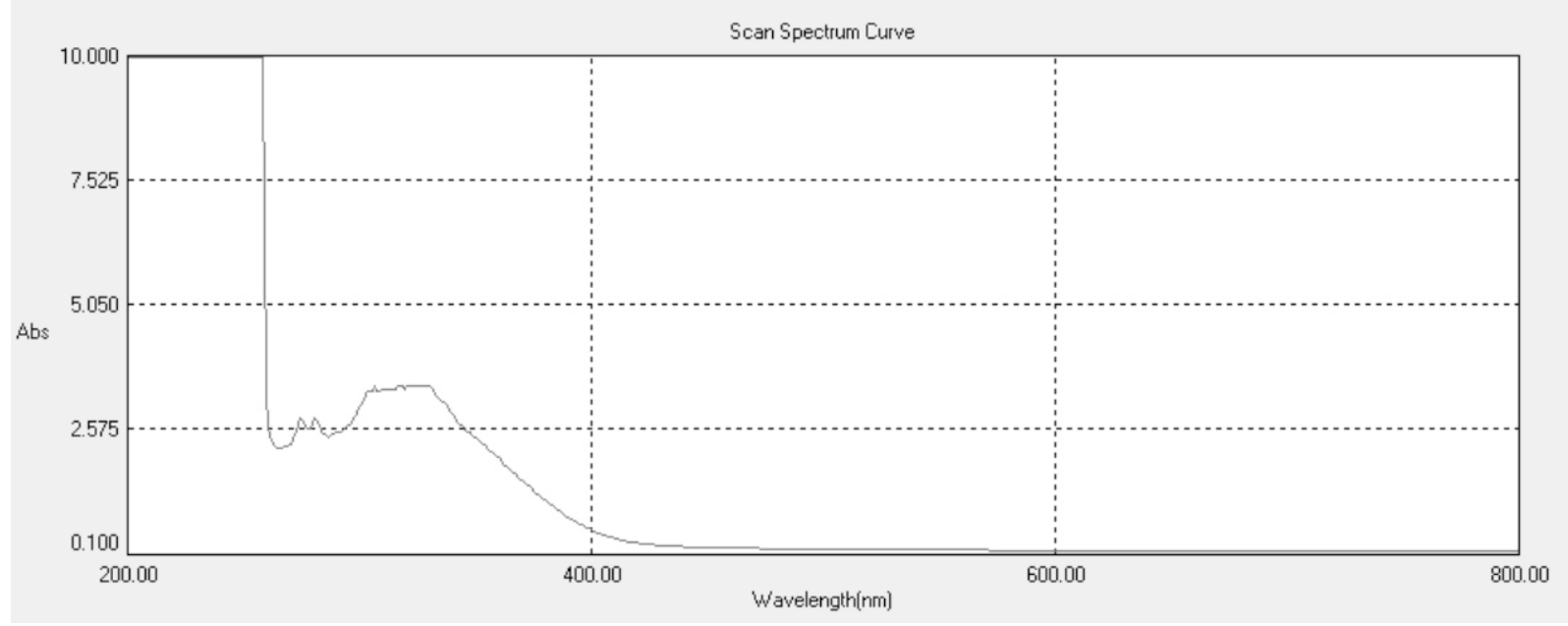

Figure 30: UV-Visible spectrum of $\mathrm{Zn}$ - guanidinophosphonatebenzimidazole complex 